\title{
Design and Empirical Analysis of Selected Machine Elements from Composite Materials is Better to Use
}

\section{Alie Wube Dametew*}

School of Mechanical and Industrial Engineering, Kombolcha Institute of Technology, Wollo University, Ethiopia

\begin{abstract}
Weight reducing weights, improving mechanical properties and maintaining strength of mechanical components are critical task in all manufacturing industries. However, this compressive advantage was achieved by the proper design, manufacturing and material selection of composite materials. Thus, the objective of this paper was to design and analyse a composite tailstock dead centre support to improve the traditional metallic material tailstock dead centre supports. Since, this replacement of composite materials for traditional metallic materials have many advantages because of higher specific stiffness, wear resistance, light weight, and strength of composite materials. In this empirical study was included and addressed with the replacement of conventional steel tailstock dead centre support from composite materials. Since the HS Glass/Epoxy is used as composite material and the weight minimization improving design parameters were done in the study. However the design optimization analysis indicates that, there was significant improvement is observed in the performance of tailstock dead centre support (in terms of weight, strength, thermal resistance). The study also attempt analyses has the deflection, the effects of stresses, wear-resistance, thermal effect natural frequencies under subjected loads using mathematical analysis were done. In the conclusion, the study investigates that light weight, safe and economical tailstock supports are made from HS carbon/Epoxy material using filament winding process. As well supplementary evaluation carried out for both steel and composite materials and weight of the tailstock dead centre support is optimized and stress intensity factor found for both Steel and composite tailstock dead centre support will consider.
\end{abstract}

Keywords: Composite material; Optimization; Design and analysis; Filament winding; Tailstock dead center support; Mathematical analysis

Abbreviations: (K): Number of possible decisions, to selection criteria; $\sigma 1$ and $\sigma 2$ : Unidirectional Lamina (Analysis) lateral and longitudinal stress; $\rho$ : Specific density of the given materials; Q: Stiffness matrix for the layer of composite materials; $S$ : The reduced compliance matrix of composite materials; E: The elasticity constant of composite materials; V: The positions ration(constants); $[Q]$ : The transformed reduced stiffness matrix in a composite material; [A], [B], [D]: Matrices are called the extensional, coupling and bending stiffness matrices. respectively, the composite material analysis

\section{Introduction and Background}

A composite is a heterogeneous substance consisting of two or more materials which does not lose the characteristics of each component. Since this combination of materials improve and brings about new desirable properties. However, the advanced composite materials such as Graphite, Carbon, Kevlar and Glass with suitable resins are widely used because of their high specific strength (strength/ density) and high specific modulus (modulus/density) [1]. Advanced composite materials seem ideally suited for long, power driver shaft and mechanical supporting applications. Their elastic properties can be tailored to increase the torque they can carry as well as the rotational speed at which they operate. Although, mechanical supporters are used in industrial machinery and aerospace applications from composite materials. Manufacturing industry is exploiting composite material technology for structural components in order to obtain the reduction of the weight without decrease in machine quality and reliability [2]. Since tailstock dead centre support is one of the most widely used machine components in manufacturing industry. While, the two main functional requirements of tailstock deeded centre support are the transmission of static and dynamic tensional loads and the high fundamental bending natural frequency to avoid whirling vibration at a high rotational speed. In most caste tailstock supports made of conventional material such as aluminium and mild steel. Theses conventional materials do not satisfy these functional requirements of tailstock deeded centre support simultaneously because they have lower specific stiffness, which limits the magnitude of fundamental bending natural frequency. Hence this study designed to investigate the material that full fill within the requirement of tailstock supports with optimum cost and production techniques. This contributes for production improvement, quality and sustainability of using simple materials for mechanical components. Also reduce unnecessary cost invest to buy conventional metal products.

\section{General Objective}

Design and analysis of composite tail stock dead centre supports to replace traditional material so as to improve their mechanical requirements.

\section{Specific Objectives}

- Select the appropriate material and manufacturing process for the Tailstock support.

- Develop the design analysis and load acting and evaluating various property of tailstock support.

*Corresponding author: Alie Wube Dametew, School of Mechanical and Industria Engineering, Kombolcha Institute of Technology, Wollo University, Ethiopia, Tel: +251913032751; E-mail: wubealie@gmail.com

Received May 27, 2017; Accepted June 12, 2017; Published June 19, 2017

Citation: Dametew AW (2017) Design and Empirical Analysis of Selected Machine Elements from Composite Materials is Better to Use. Int J Swarm Intel Evol Comput 6: 157. doi: 10.4172/2090-4908.1000157

Copyright: ( 2017 Dametew AW. This is an open-access article distributed unde the terms of the Creative Commons Attribution License, which permits unrestricted use, distribution, and reproduction in any medium, provided the original author and source are credited. 
- Improve Functional Requirements of Tailstock supports.

- Show the economical analysis and functional merits of composite materials.

\section{Research Methodology}

The study was conduct through literature review of research articles, books, magazines, manuals, company report and electronicsources which are discuss related to design, manufacturing mechanics of composite materials in relation to the conventional steel machine elements. The analysis was done with mathematical methods and the analysis consider attempts to investigate and replace optimum performance tailstock dead centre support from composite materials, so as to improve weight, const, stiffness, thermal resistance and the entire mechanical property of the selected machine components. Since, the design, manufacturing economic analysis and evaluation of the project was done using the selected empirical analysis. Finally the conclusion and recommendation of the study is given below.

\section{Literature Review}

\section{Introduction}

Composite materials are combination of two or more constituents differing in form and/or material composition and that are essentially insoluble in each other. Both constituents maintain their identity as they do not solve or melt in each other. Since act in such a way, that new material results who are properties are better than the sum of their constituents. In practice, most composites consist of a bulk material (the matrix) and a reinforcement of some kind, added primarily to increase the strength and stiffness of the matrix [2]. This reinforcement is usually in fibre form. Composites materials have advantageous than conversational materials because of specific strength and stiffness, tailored design, fatigue life, dimensional stability, corrosion resistance, cost-effective fabrication $[3,4]$.

\section{Classification of composites}

Composite materials can be classified as Fibber and Matrix. The matrixes are Polymer matrix composites, metal matrix composites, Ceramic matrix.

\section{Matrices}

Matrix also acts as binder, a load transfer medium between the fibres and protects them from environmental damages due to elevated temperatures, humidity and corrosion. The failure mode is strongly affected by the type of matrix material used in the composite as well as its compatibility with the fibber. Since, matrices can be thermoplastic or thermosetting resins, minerals and metallic. Usual resins are polyesters, phenolic, melamine, silicone, polyurethane and epoxy. Mineral matrices, like silicon, carbide or carbon, are capable to withstand high temperatures [5].

\section{Reinforcements}

The role of reinforcement in a composite is to increase mechanical properties of neat resin, like stiffness, tensile strength, hardness or others. They can equally improve physical, chemical or electrical properties. Reinforcement materials shall have high mechanical properties, low density, good resin compatibility, is easy to manufacture and low cost, among others. Reinforcements can be distributed in the following ways:

- One-dimensional, when fibres are oriented towards one direction.
- Bi-dimensional, or according to a plan, in tissue or non-tissue surfaces.

- Tri-dimensional, in pre-shaped volumes or not, if fibres are oriented according to more than two dimensions in space. The mechanical strength of a composite is determined by fibre orientation as well as the direction that presents higher properties.

\section{Hybrids composites}

The term hybrid refers to a composite that has more than one type of matrix or fibre in its construction. The use of hybrid composites can expand the range of achievable Properties when using composite materials and can be more cost-effective than conventional or advanced composites. One of the main attractive when using hybrids is their synergy effect also called as 'hybrid effect'. The most common effect is to obtain a composite property, like tensile strength, whose value is higher than would be predicted from a simple application of the rule of mixtures. This would be a positive hybrid effect. In some cases, a negative effect may also occur. The term hybrid applies to advanced composites using various combinations of graphite, boron, Kevlar or glass filaments in a thermosetting or thermoplastic matrix. Hybrids have unique features that can be used to meet design requirements in a more cost-effective way than advanced or conventional composites. Some of those advantages are the balanced strength and stiffness, balanced thermal distortion, reduced weight and/or cost, improved fatigue resistance, reduced notch sensitivity, improved fracture toughness and impact resistance [3].

\section{Design Procedure}

The design of composite structure is complicated by the fact that every different material properties used must be defined. Engineering drawings must describe the ply orientation, its position within the stack and its boundaries. This is straightforward for a simple, constant thickness laminate. For complex parts with tapered thicknesses and ply build-ups around joints and cut outs, this can become extremely complex. The need to maintain relative balance and symmetry throughout the structure increases the difficulty. Composites cannot be designed without concurrence. Design details depend on tooling and processing as does assembly and inspection. Parts and processes are so interdependent it could be disastrous to attempt sequential design and manufacturing phasing [6] (Figure 1).

\section{Selection of manufacturing process}

Before selecting raw materials for composite manufacturing, it is mandatory to determine the appropriate manufacturing techniques. Because, the material we select prior to manufacturing technique may not be processed by the available method, which leads to wastage of time, labour and money. Therefore, unlike to conventional materials such as metals, selection of manufacturing technique precedes material selection.

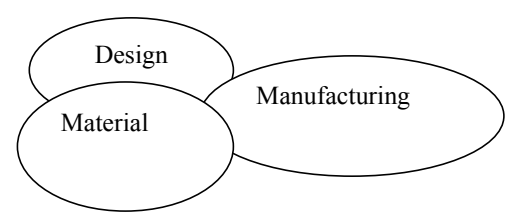

Figure 1: The design procedure of composite materials. 


\section{Composite fabrication processes include:}

1. Prepreg lay-up is expensive but produces the highest-quality parts. Prepreg parts are usually cured in an autoclave to maximize part quality.

2. Wet lay-up along with low-temperature curing resins, is capable of making very large structures. It is an excellent process for low-volume large parts. Wet laid-up parts can be cured with or without a vacuum bag.

3. Spray-up is another process capable of making very large part size. Due to the random discontinuous nature of the fibbers, the mechanical properties are lower than parts made by continuous fibber prepreg or Wet lay-up.

4. Liquid-moulding processes use a dry perform that is placed in a Matched-die tool, liquid resin is injected and the part is cured in the mold. The resin can be injected under pressure or pulled through perform with a vacuum.

5. Compression molding is another matched-die process that uses either SMCs or BMCs that is loaded as a predetermined charge. Heat and pressure form and cure the part to the required shape

6. Injection molding is a high-volume process capable of making millions of parts per year. A thermoplastic or thermo set resin reinforced with short fibbers is injected into precision mould under high pressures, where it either cools (thermoplastic) or cures (thermo set).

7. Pultrusion is a continuous process for making structural shapes of constant cross-section. Roving is normally pulled through a resin bath and into a heated die where the part cures as it travels through the die. It is then pulled to the desired length and cut with a mechanical saw. Pultrusion is used for the manufacture of components having continuous lengths and a constant crosssectional shape (i.e., rods, tubes, beams, etc.) (Figure 2).

8. Filament winding is a process capable of making parts that are bodies of revolution or near bodies of revolution. Filament winding can be conducted by using either prepreg roving or wet winding (Figure 3)

9. Resin Transfer Moulding (RTM) and Reaction Injection Moulding Process (IM) also used to manufacture composite products.

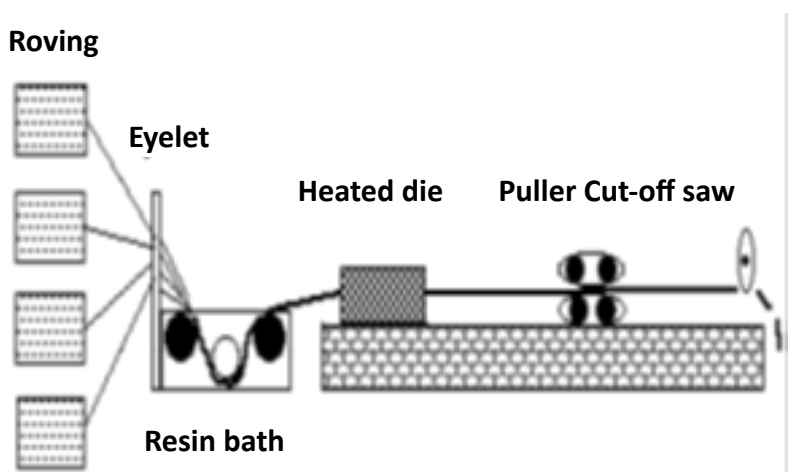

Figure 2: Pultrusion process.

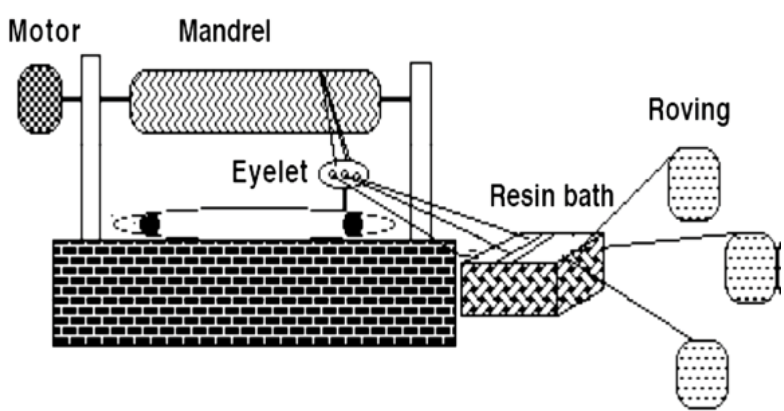

Figure 3: Filament winding process

\section{Mathematical Analysis}

\section{A manufacturing process selection using digital logical method}

Since to the selection criteria for determining the appropriate manufacturing process of tailstock dead centre support includes Production rate, shape, cost, size and flexibility were considered as selection criteria. However, using digital logic method, the total number of possible decisions, $(\mathrm{K})$, is given by:

$K=\frac{n(n-1)}{2}$

Where, $\mathrm{n}=$ number of parameters under consideration (5).

$K=\frac{5(5-1)}{2}=10$ number of decisions (Tables 1 and 2).

The above table indicates that, from numerous type of composite, appropriate process is selected based on the given parameters (production rate, cost, flexibility, shape and sizes) are considered as a selection criteria. Since based on the weighting factor and production parameters given above in Tables 1 and 2 as an input, the optimum manufacturing process were selected for the production of tailstock dead centre support. Hence, based on the above inputs the selection process was done in the Tables 3 and 4.

The digital logic method show from the above analysis the optimum manufacturing process among the candidate manufacturing techniques

\begin{tabular}{|l|c|c|c|c|c|}
\hline Factors & Production rate & Cost & Flexibility & Size & Shape \\
\hline Weighing factor & 2.9 & 2.6 & 2.5 & 1 & 1 \\
\hline Weighting Factor (\%) & 0.80 & 0.23 & 0.26 & 0.17 & 0.13 \\
\hline
\end{tabular}

Table 1: Weighting factor

\begin{tabular}{|l|c|c|c|c|c|}
\hline Process & Production rate & Cost & Flexibility & Size & Shape \\
\hline Injection molding & 80 & 75 & 65 & 60 & 80 \\
\hline Filament winding & 80 & 70 & 85 & 70 & 95 \\
\hline Putruaion & 90 & 80 & 60 & 70 & 95 \\
\hline SRIM & 50 & 60 & 65 & 50 & 55 \\
\hline Hand lay up & 40 & 35 & 75 & 50 & 60 \\
\hline
\end{tabular}

Table 2: Manufacturing process and decision.

\begin{tabular}{|l|c|c|c|c|c|}
\hline Process & Production rate & Cost & Flexibility & Size & Shape \\
\hline Injection molding & $80 x .80$ & $75 x .23$ & $65 x .26$ & $60 x .17$ & $80 x .13$ \\
\hline Filament winding & $80 x .80$ & $70 x .23$ & $85 x .26$ & $70 x .17$ & $95 x .13$ \\
\hline Putruaion & $84 x .80$ & $80 x .23$ & $60 x .26$ & $70 x .17$ & $95 x .13$ \\
\hline SRIM & $50 x .80$ & $60 x .23$ & $65 x .26$ & $50 x .17$ & $55 x .13$ \\
\hline Hand lay up & $40 x .80$ & $35 x .23$ & $75 x .26$ & $50 x .17$ & $60 x .13$ \\
\hline
\end{tabular}

Table 3: Manufacturing process with weighting factor. 


\begin{tabular}{|l|c|c|c|c|c|c|c|}
\hline Process & $\begin{array}{c}\text { Production } \\
\text { rate }\end{array}$ & Cost & Flexibility & Size & Shape & Total & Rank \\
\hline Injection molding & 64 & 17.23 & 16.90 & 10.20 & 10.40 & 118.73 & 3 \\
\hline Filament winding & 64 & 16.10 & 22.10 & 11.90 & 12.35 & 126.45 & 1 \\
\hline Putruaion & 67.2 & 18.40 & 15.60 & 11.90 & 12.35 & 125.45 & 2 \\
\hline SRIM & 40 & 13.80 & 16.90 & 8.50 & 7.15 & 86.35 & 4 \\
\hline Hand lay up & 32 & 8.05 & 19.50 & 8.50 & 7.80 & 75.85 & 5 \\
\hline
\end{tabular}

Table 4: Weighting result and manufacturing process selection.

of composite material are filament winding. Hence filament winding is the beast manufacturing techniques for the production of tailstock dead centre support. Thus this tailstock dead centre support is manufacture using filament winding process and $i$ have selected this production technique.

\section{Materials Selection}

With growing technological advancement, community awareness and customer needs, ignorance of opportunities offered by advanced material systems such as composite materials can cause decreased competitiveness and can lead to loss of market. With the increase in customer demand for higher performance and quality, competition among companies has increased. To capture the global market and be at the cutting edge of the technology, companies are utilizing new and advanced materials for increased performance. In light of global needs and environmental awareness, lightweight materials are gaining importance in various industry sectors. There are two major reasons why an engineer becomes involved in the material selection process [4].

1. To redesign an existing product for better performance, lower cost, increased reliability, decreased weight, etc.

2. To select a material for a new product or application. In either case, mere material substitution is not sufficient. The product must be redesigned for the selected material to utilize the maximum benefits of the material's properties and processing characteristics. When a composite material is substituted for a steel or aluminium product, the part needs to be redesigned to obtain the cost and weight benefits. Based on the requirements of an application, possible materials and manufacturing processes that meet minimum or maximum requirements of the application are determined. Materials and manufacturing processes are discussed simultaneously because they go hand in hand with composite material systems. Candidate composite materials, which are selected for comparison with respect to functional requirements of tailstock dead centre support, are: 20\% sic reinforced Al-composite, E-glass /epoxy, Carbon/ Epoxy and Kevlar/ Epoxy. However in this study the material selection process follows the following stages and methods. This included, general material performance requirements, initial screening of the candidate material, material selection using digital logic method and Optimum material selection.

\section{General material performance requirements}

In manufacturing of tailstock dead centre support the following main properties and requirements have to be considered as stated in the introduction part. Those are: Strength/stiffness, High resistance to Failure strain (\%), Wear resistance, Optimum cost and Friction coefficient.

\section{Initial screening of the candidate material}

Traditional material for tailstock support is Mild steel. The strength, wear resistance, of mild steel is low which Allows improper supporting and poor product are produced. Following will describe the potential candidate materials those can be used for tailstock dead centre support application.

\section{a) $20 \%$ sic reinforced $\mathrm{Al}$-composite:}

Aluminium is the most popular matrix for the metal matrix composites (MMCs). The alloys are quite attractive due to their low density, their capability to be strengthened by precipitation, their good corrosion resistance, high thermal and electrical conductivity, and their high damping capacity. Aluminium matrix composites (AMCs) have been widely studied since the 1920s and are now used in sporting goods, electronic packaging, armours, manufacturing and automotive industries. They offer a large variety of mechanical properties depending on the chemical composition of the Al-matrix.

HS Carbon/Epoxy carbon fibbers are thin filaments made of elementary carbon with structures that vary from those of the amorphous carbon to those of the crystalline graphite offer the highest strength and stiffness of all commonly used reinforcement fibbers. The fibbers are not subject to stress rupture or stress corrosion, as with glass and aramids. High temperature performance is particularly outstanding. Although, in specific applications where both high resistance and high rigidity are needed, fibrous reinforcements must be chosen. Since, here are the factors with their weighting factor according to the importance of the properties (Table 5).

The Table 5 shows the weighting factors, of the given material selection parameters, that would set to select appropriate composite materials based on mechanical properties the tailstock dead centre centres. Since using the above weighting factors value and the parameters listed in Table 5, the optimum material was selected below using Digital logic Method.

\section{Material selection using digital logic method}

The digital logic method can be employed for the optimum material selection using with ranking, obtained from the analysis results (Tables 6-9).

The material selection analysis was done from Tables 6 to 9. Since, from the analysis of digital logic method, indicates that, HS Carbon/Epoxy material have the highest performance index from the given candidate materials. Since, HS Carbon/Epoxy is an optimum material among the candidate materials of tailstock dead centre support. Thus, based on the

\begin{tabular}{|l|c|c|}
\hline Materials & Positive decisions & Weighting factor \\
\hline strength/stiffness & 1 & 0.1 \\
\hline High resistance to Failure strain (\%) & 2 & 0.2 \\
\hline Wear resistance & 3 & 0.3 \\
\hline Cost & 3 & 0.3 \\
\hline Friction coefficient & 1 & 0.1 \\
\hline
\end{tabular}

Table 5: Weighting factors.

\begin{tabular}{|c|c|c|c|c|c|c|c|c|c|c|}
\hline \multirow[b]{2}{*}{ Property } & & & & & & & & & & \\
\hline & 1 & 2 & 3 & 4 & 5 & 6 & 7 & 8 & 9 & 10 \\
\hline Strength/stiffness (Mpa) & 0 & 0 & 0 & 1 & & & & & & \\
\hline High resistance to Failure strain (\%) $(0.1)$ & 1 & & & & 1 & 0 & 1 & & & \\
\hline Wear resistance $(0.2)$ & & & 1 & & & 0 & & & 1 & 1 \\
\hline Cost -(0.3) & & & & 1 & & & 1 & & 0 & 1 \\
\hline Friction coefficient 0.3 & & & 1 & & & 1 & & & 0 & 0 \\
\hline Strength/stiffness (Mpa) (0.1) & & & & & 0 & & & & 0 & 1 \\
\hline
\end{tabular}

Table 6: Properties of candidate materials for tailstock dead centre support. 
Citation: Dametew AW (2017) Design and Empirical Analysis of Selected Machine Elements from Composite Materials is Better to Use. Int J Swarm Intel Evol Comput 6: 157. doi: 10.4172/2090-4908.1000157

\begin{tabular}{|c|c|}
\hline Materials & Longitudinal strength/stiffness (Mpa) \\
\hline $20 \%$ Sic reinforced Al-composite & 406 \\
\hline E-glass/Epoxy & 800 \\
\hline Carbon/Epoxy & 880 \\
\hline Kevlar/Epoxy & 825 \\
\hline
\end{tabular}

Table 7: Candidate material with stiffness value for selection analysis.

\begin{tabular}{|l|c|c|c|c|}
\hline Property & $\begin{array}{c}\mathbf{1 2 0 \%} \text { Sic } \\
\text { reinforced Al- } \\
\text { composite }\end{array}$ & $\begin{array}{c}\text { E-glass/ } \\
\text { Epoxy }\end{array}$ & $\begin{array}{c}\text { HS Carbon/ } \\
\text { Epoxy }\end{array}$ & $\begin{array}{c}\text { Kevlar/ } \\
\text { Epoxy }\end{array}$ \\
\hline Strength/stiffness (Mpa) & $406 x .1$ & $800 x .1$ & $880 x .1$ & $825 x .1$ \\
\hline $\begin{array}{l}\text { High resistance to Failure } \\
\text { strain (\%) (0.1) }\end{array}$ & $41 \times .1$ & $50 x .1$ & $80 x .1$ & $90 x .1$ \\
\hline Wear resistance (0.2) & $3.25 \times .2$ & $2.91 \times .2$ & $3.82 x .2$ & $3.83 x .2$ \\
\hline Cost - (0.3) & $50 x .3$ & $55 x .3$ & $60 x .3$ & $\begin{array}{c}70 x .3 \text { v. high } \\
\text { cost }\end{array}$ \\
\hline Friction coefficient 0.3 & 0.35 & 0.44 & 0.66 & 0.60 \\
\hline
\end{tabular}

Table 8: Rating with factor.

\begin{tabular}{|c|c|c|c|c|}
\hline \multirow[b]{2}{*}{ Property } & \multicolumn{4}{|c|}{ Values of Candidate materials } \\
\hline & $\begin{array}{c}120 \% \text { Sic } \\
\text { reinforced Al- } \\
\text { composite }\end{array}$ & $\begin{array}{l}\text { E-glass/ } \\
\text { Epoxy }\end{array}$ & $\begin{array}{l}\text { HS Carbon/ } \\
\text { Epoxy }\end{array}$ & $\begin{array}{l}\text { Kevlarl } \\
\text { Epoxy }\end{array}$ \\
\hline Strength/stiffness (Mpa) & 40.6 & 80.0 & 88.0 & 82.5 \\
\hline $\begin{array}{l}\text { High resistance to Failure } \\
\text { strain }(\%)(0.1)\end{array}$ & 4.1 & 5.0 & 8.0 & 9.0 \\
\hline Wear resistance $(0.2)$ & 0.63 & 0.582 & 0.764 & 0.66 \\
\hline Cost -(0.3) & 15 & 16.5 & 18 & 21 \\
\hline Friction coefficient 0.3 & 0.35 & 0.44 & 0.66 & 0.60 \\
\hline total & 60.68 & 102.52 & 115.42 & 113.76 \\
\hline Rank & 4 & 3 & 1 & 2 \\
\hline
\end{tabular}

Table 9: Final result and selection of the candidate material.

given clitoral and analysis results, HS Carbon/Epoxy is the beast material for designing of tailstock dead centre support. Hence, traditional steel tailstock dead centre support should replace by the selected candidate materials so as to improve the performance and capacity of the them.

\section{Stress-strain relationship for unidirectional lamina (analysis)}

During stress analysis of composite materials we have to follow and use different assumptions and mathematical models.

\section{Assumptions}

- The tailstock dead centre support has a uniform, circular cross section.

- The tailstock dead centre support perfectly balanced

- All damping and nonlinear effects are excluded.

- The stress-strain relationship for composite material is linear and elastic; hence, Hooke's law is applicable for composite materials.

- Since lamina is thin and no out of plane loads are applied, it is considered as under the plane stress.

The lamina is thin and if no out-of-plane loads are applied, it is considered as the plane stress problem. Hence, it is possible to reduce the 3-D problem into $2-\mathrm{D}$ problem. A condition of plane stress with all stress components in the out of plane direction (3-direction) being zero, i.e., $\sigma_{3}=0, \tau_{23}=\tau_{4}=0, \tau_{13}=\tau_{5}=0$. However for unidirectional 2-D lamina, the stress-strain relationship in terms of physical material direction is given by [7] (Table 10).

$$
\left[\begin{array}{l}
1 \\
2 \\
6
\end{array}\right]=\left[\begin{array}{ccc}
\mathrm{Q} 11 & \mathrm{Q} 12 & 0 \\
\mathrm{Q} 12 & \mathrm{Q} 22 & 0 \\
0 & 0 & \mathrm{Q} 66
\end{array}\right]\left[\begin{array}{l}
1 \\
2 \\
6
\end{array}\right]
$$

NB the following variable is computing using the above data, i.e., (HS Carbon/Epoxy y). The matrix Q is referred as the reduced stiffness matrix for the layer and its terms are given by:

$$
\begin{gathered}
Q 11=\frac{E 1}{1-V 12 V 21}=134.633 \mathrm{Gpa} \\
Q 22=\frac{E 2}{1-V 21 V 12}=7.033 \mathrm{Gpa} \\
Q 66=G 12 \\
Q 12=Q 21=\frac{V 12 E 2}{1-V 12 V 21}=2.11 \mathrm{Gpa} \\
V 21=\frac{V 12 E 2}{E 1}=0.01567 \\
{[\mathrm{Q}]=\left[\begin{array}{ccc}
Q 11 & Q 12 & 0 \\
Q 21 & Q 22 & 0 \\
0 & 0 & Q 66
\end{array}\right]}
\end{gathered}
$$

The reduced compliance matrix [S] components

$$
\begin{aligned}
& s_{11=} \frac{1}{E_{1}}=7.463 \times 10^{-10} \mathrm{pa} \\
& s_{12}=\frac{-\vee_{12}}{E 1}=-2.238 \times 10^{-10} \mathrm{pa} \\
& s_{22}=\frac{1}{E_{2}}=0.143 \times 10^{-9} \mathrm{pa}
\end{aligned}
$$$$
s_{66}=\frac{1}{G_{12}}=0.172 \times 10^{-9} \mathrm{pa}
$$$$
s_{16}=s_{26}=0
$$$$
[S]=\left[\begin{array}{ccc}
7.463 \times 10^{-10} & -2.238 \times 10^{-10} & 0 \\
-2.238 \times 10^{-10} & 0.143 \times 10^{-9} & 0 \\
0 & 0 & 0.172 \times 10^{-9}
\end{array}\right] \times \mathrm{pa}
$$

Calculating strains at Fiber axis are given by:

\begin{tabular}{|c|c|c|c|c|c|}
\hline S. No. & Property & Unit s & $\begin{array}{c}\text { E-Glass/ } \\
\text { Epoxy y }\end{array}$ & $\begin{array}{c}\text { HS Carbon/ } \\
\text { Epoxy y }\end{array}$ & $\begin{array}{c}\text { HM Carbon/ } \\
\text { Epoxy xy }\end{array}$ \\
\hline 1. & $\mathrm{E} 11$ & $\mathrm{GPa}$ & 50.0 & 134.0 & 190.0 \\
\hline 2. & $\mathrm{E} 22$ & $\mathrm{GPa}$ & 12.0 & 7.0 & 7.7 \\
\hline 3. & $\mathrm{G} 12$ & $\mathrm{GPa}$ & 5.6 & 5.8 & 4.2 \\
\hline 4. & $\mathrm{~V} 12$ & - & 0.3 & 0.3 & 0.3 \\
\hline 5. & $\sigma 1^{\top}=\sigma 1^{\mathrm{c}}$ & $\mathrm{MPa}$ & 800.0 & 880.0 & 870.0 \\
\hline 6. & $\sigma 2^{\top}=\sigma 2^{\mathrm{c}}$ & $\mathrm{MPa}$ & 40.0 & 60.0 & 54.0 \\
\hline 7. & $\sigma 12$ & $\mathrm{MPa}$ & 72.0 & 97.0 & 30.0 \\
\hline 8. & $\rho$ & $\mathrm{Kg} / \mathrm{m} 3$ & 2000.0 & 1600.0 & 1600.0 \\
\hline
\end{tabular}

Table 10: Mechanical properties for each lamina of the laminate. 
$[\varepsilon]=[s][\sigma]$

$\left[\begin{array}{c}€ 1 \\ 2 \\ 6\end{array}\right]=\left[\begin{array}{ccc}7.463 \times 10^{-10} & -2.238 \times 10^{-10} & 0 \\ -2.238 \times 10^{-10} & 0.143 \times 10^{-9} & 0 \\ 0 & 0 & 0.172 \times 10^{-9}\end{array}\right]\left[\begin{array}{c}880 \times 10^{6} \\ 0 \\ 0\end{array}\right]$

$\left[\begin{array}{c}€ 1 \\ 2 \\ 6\end{array}\right]=\left[\begin{array}{c}0.6567 \\ -0.1969 \\ 0\end{array}\right]$

The design variables include, stacking sequence, number of plies, thickness of the ply and stacking sequence.

From the above analysis, design using HS Carbon/Epoxy y Lamina only the load is shearing one, the tailstock dead centre support made of 4 plies of HS Carbon/Epoxy y composite is proposed. But, this object fulfilled the requirement of tensional strength only but not the tensional buckling and natural frequency requirement. To calculate the tensional strength Tsai-Wu failure criterion is used. Since the hoop modulus has an important effect on tensional buckling and is likely to require that fibbers be placed in the hoop direction to achieve an adequate buckling strength. Some fibres' be placed in the axial direction to achieve sufficient in-plane axial stiffness due to these [0/90/0/45/90/-45 laminate fulfilled all the requirements for tailstock dead centre support. Therefore the stacking sequences are written as [0/90/0/45/90/-45] (Table 11).

Thickness of the surface=the diameter of the Dead centre support=22 $\mathrm{mm}$ (by measuring the object).

Number of plies $=$ thickness of the wall $/$ ply thickness $=22 / 0.688=32$, Ply thickness $=0.688$ (from Composite materials by Daniel Gay) [8]

The transformed reduced stiffness matrix $[\bar{Q}]$

$\mathrm{M}=\operatorname{Cos} \theta, \mathrm{N}=\operatorname{Sin} \theta$,

If $\theta=0, M=\operatorname{Cos} 0=1, N=\operatorname{Sin} 0=0$,

If $\theta=90, M=\cos 90=0, N=\operatorname{Sin} 90=1$

if $\theta=45, \mathrm{M}=\mathrm{N}=\cos 45=\sin 45=0.707=0.7$

If $\theta=-45, M=\cos -45=0.707=0.7, N=\sin -45=-0.707=-0.7$

$$
\begin{gathered}
Q 11=\frac{E 1}{1-V 12 V 21}=134.633 G p a \\
Q 22=\frac{E 2}{1-V 21 V 12}=7.033 G p a \\
Q 66=G 12 \\
Q 12=Q 21=\frac{V 12 E 2}{1-V 12 V 21}=2.11 G p a \\
Q 16=Q 61=Q 26=Q 62=0 \\
V 21=\frac{V 12 E 2}{E 1}=0.01567
\end{gathered}
$$

The transformed reduced stiffness matrix $[\bar{Q}]_{0}$ is as follows:

\begin{tabular}{|c|c|l|}
\hline ho=-2.09 & $0^{\circ}$ & $0.68 \mathrm{~mm}$ \\
\hline $\mathrm{h} 1=-1.402$ & $90^{\circ}$ & $0.68 \mathrm{~mm}$ \\
\hline $\mathrm{h} 3=2.09$ & $0^{\circ}$ & $0.68 \mathrm{~mm}$ \\
\hline $\mathrm{h} 4=0.714$ & $45^{\circ}$ & $0.68 \mathrm{~mm}$ \\
\hline $\mathrm{h} 5=1.402$ & $90^{\circ}$ & $0.68 \mathrm{~mm}$ \\
\hline $\mathrm{h} 6=0.714$ & $-45^{\circ}$ & $0.68 \mathrm{~mm}$ \\
\hline
\end{tabular}

Table 11: Number of plies should be calculated in the following way.
At $\theta=0$

$\bar{Q}_{11}=\mathrm{Q}_{11} \mathrm{M}^{4}+2\left(\mathrm{Q}_{12}+2 \mathrm{Q}_{66}\right) \mathrm{N}^{2} \mathrm{M}^{2}+\mathrm{Q}_{22} \mathrm{~N}^{4}=\mathrm{Q}_{11}=143.63 \times 10^{9 \mathrm{pa}}$

$\overline{\mathrm{Q}}_{22}=\mathrm{Q}_{11} \mathrm{~N}^{4}+2\left(\mathrm{Q}_{12}+2 \mathrm{Q}_{66}\right) \mathrm{N}^{2} \mathrm{M}^{2}+\mathrm{Q}_{22} \mathrm{M}^{4}=\mathrm{Q}_{22}=7.033 \times 10^{9} \mathrm{pa}$

$\overline{\mathrm{Q}}_{12}=\left(\mathrm{Q}_{11}+\mathrm{Q}_{22}-4 \mathrm{Q}_{66}\right) \mathrm{N}^{2} \mathrm{M}^{2}+\mathrm{Q}_{12}\left(\mathrm{~N}^{4}+\mathrm{M}^{4}\right)=\mathrm{Q}_{12}=2.11 \times 10^{9 \mathrm{~Pa}}$

$\overline{\mathrm{Q}}_{16}=\left(\mathrm{Q}_{11}-\mathrm{Q}_{22}-2 \mathrm{Q}_{66}\right) \mathrm{N} \mathrm{M}^{3}+\left(\mathrm{Q}_{12}-\mathrm{Q}_{22}+2 \mathrm{Q}_{66}\right) \mathrm{N}^{3} \mathrm{M}=0$

$\overline{\mathrm{Q}}_{26}=\left(\mathrm{Q}_{11}-\mathrm{Q}_{22}-2 \mathrm{Q}_{66}\right) \mathrm{N}^{3} \mathrm{M}+\left(\mathrm{Q}_{12}-\mathrm{Q}_{22}+2 \mathrm{Q}_{66}\right) \mathrm{N} \mathrm{M}^{3}=0$

$\overline{\mathrm{Q}}_{66}=\left(\mathrm{Q}_{11}+\mathrm{Q}_{22}-2 \mathrm{Q}_{12}-2 \mathrm{Q}_{66}\right) \mathrm{N}^{2} \mathrm{M}^{2}+\mathrm{Q}_{66}\left(\mathrm{~N}^{4}+\mathrm{M}^{4}\right)=\mathrm{Q}_{66}=5.8 \times 10^{9}$

$[\bar{Q}]_{0}=\left[\begin{array}{lll}\overline{Q_{11}} & \overline{Q_{12}} & \overline{Q_{16}} \\ \overline{Q_{12}} & \overline{Q_{22}} & \overline{Q_{26}} \\ \overline{Q_{16}} & \overline{Q_{26}} & \overline{Q_{26}}\end{array}\right]$

$[\bar{Q}]_{0}=\left[\begin{array}{crr}134.633 \times 10^{9} & 2.11 \times 10^{9} & 0 \\ 2.11 \times 10^{9} & 7.033 \times 10^{9} & 0 \\ 0 & 0 & 5.80 \times 10^{9}\end{array}\right]$

Lamina direction at $\theta=90$

$[\bar{Q}]_{90}=\left[\begin{array}{lll}\overline{Q_{11}} & \overline{Q_{12}} & \overline{Q_{16}} \\ \overline{Q_{16}} & \overline{Q_{22}} & \overline{Q_{26}} \\ \overline{Q_{26}}\end{array}\right]$

$\left[{ }^{Q}\right]_{90}=\left[\begin{array}{ccc}7.033 \times 10^{9} & 2.11 \times 10^{9} & 0 \\ 2.11 \times 10^{9} & 134.63 \times 10^{9} & 0 \\ 0 & 0 & 5.80 \times 10^{9}\end{array}\right]$

At $\theta=45$

$[\bar{Q}]_{45}=\left[\begin{array}{lll}\overline{Q_{11}} & \overline{Q_{12}} & \overline{Q_{16}} \\ \overline{Q_{16}} & \overline{Q_{22}} & \overline{Q_{26}} \\ \overline{Q_{26}} & \overline{Q_{26}}\end{array}\right]$

$[\bar{Q}]_{45}=\left[\begin{array}{ccc}65.63 \times 10^{9} & 137 \times 10^{9} & 29.49 \times 10^{9} \\ 137 \times 10^{9} & 40.6 \times 10^{9} & 29.49 \times 10^{9} \\ 29.49 \times 10^{9} & 29.49 \times 10^{9} & 35.785 \times 10^{9}\end{array}\right]$

At $\theta=-45$

$[\bar{Q}]_{-45}=\left[\begin{array}{lll}\overline{Q_{11}} & \overline{Q_{12}} & \overline{Q_{16}} \\ \overline{Q_{12}} & \overline{Q_{22}} & \overline{Q_{26}} \\ \overline{Q_{16}} & \overline{Q_{26}}\end{array}\right]$, since at the angle of $[\bar{Q}]_{45}=$

$$
\left[\begin{array}{ccc}
65.63 \times 10^{9} & 137 \times 10^{9} & -29.45 \times 10^{9} \\
137 \times 10^{9} & 40.6 \times 10^{9} & -29.45 \times 10^{9} \\
-29.49 \times 10^{9} & 29.49 \times 10^{9} & 35.785 \times 10^{9}
\end{array}\right]
$$

Calculate $[\mathrm{A}][\mathrm{B}][\mathrm{D}]$ matrix

For a symmetric laminate, the $\mathrm{B}$ matrix vanishes and the in plane and bending stiffness's are uncoupled.

$A_{i j}=\sum_{k=1}^{n}\left[Q_{i j}\right]_{k}\left(h_{k}-h_{k-1}\right), i=1,2,6, j=1,2,6=$ Extensional stiffness 


$$
B_{i j}=\frac{1}{2} \sum_{k=1}^{n}\left[Q_{i j}\right]_{k}\left(h_{k}^{2}-h^{2}{ }_{k-1}\right), i=1,2,6, j=1,2,6=\text { Coupling }
$$
stiffness matrix

$$
D_{i j}=\frac{1}{3} \sum_{k=1}^{n}\left[Q_{i j}\right]_{k}\left(h_{k}^{3}-h_{k-1}^{3}\right), i=1,2,6, j=1,2,6=\text { Bending }
$$

stiffness matrix

Where $i, j=1,2,6$.

$[\mathrm{A}],[\mathrm{B}],[\mathrm{D}]$ matrices are called the extensional, coupling, and bending stiffness matrices respectively. While, for symmetric laminates, the $\mathrm{B}$ matrix vanishes and the in plane and bending stiffness are uncoupled. For a symmetric laminate,

$$
\begin{aligned}
& {[A]=\left[\begin{array}{ccc}
134.633 \times 10^{9} & 2.11 \times 10^{9} & 0 \\
2.11 \times 10^{9} & 7.033 \times 10^{9} & 0 \\
0 & 0 & 5.80 \times 10^{9}
\end{array}\right] \times 10^{9} \mathrm{pa}_{(2.1-(-0.714)}+} \\
& {\left[\begin{array}{crr}
7.033 \times 10^{9} & 2.11 \times 10^{9} & 0 \\
2.11 \times 10^{9} & 134.63 \times 10^{9} & 0 \\
0 & 0 & 5.80 \times 10^{9}
\end{array}\right]_{\times 10^{9} \mathrm{pa}_{(-1.4-0.714)}}} \\
& +\left[\begin{array}{ccc}
65.63 \times 10^{9} & 137 \times 10^{9} & 29.49 \times 10^{9} \\
137 \times 10^{9} & 40.6 \times 10^{9} & 29.49 \times 10^{9} \\
29.49 \times 10^{9} & 29.49 \times 10^{9} & 35.785 \times 10^{9}
\end{array}\right] \times 0^{9} \mathrm{pa}_{(-2.1-(-1.4)} \\
& +\left[\begin{array}{ccc}
65.63 \times 10^{9} & 137 \times 10^{9} & -29.45 \times 10^{9} \\
137 \times 10^{9} & 40.6 \times 10^{9} & -29.45 \times 10^{9} \\
-29.49 \times 10^{9} & 29.49 \times 10^{9} & 35.785 \times 10^{9}
\end{array}\right] \times{ }^{10^{9} \mathrm{pa}_{(1.4-(-2.1)}} \\
& {[A]=\left[\begin{array}{ccc}
547.76 \times 10^{9} & 385.1 \times 10^{9} & -123.743 \times 10^{9} \\
385.1 \times 10^{9} & -151.14 \times 10^{9} & -123.743 \times 10^{9} \\
-123.743 \times 10^{9} & 123.743 \times 10^{9} & 104.26 \times 10^{9}
\end{array}\right] \mathrm{pa}} \\
& \text { Coupling stiffness matrix }[\mathrm{B}] \\
& B_{i j}=\frac{1}{2} \sum_{k=1}^{n}\left[Q_{i j}\right]_{k}\left(h_{k}^{2}-h_{k-1}^{2}\right), i=1,2,6, j=1,2,6=\text { Coupling }
\end{aligned}
$$

stiffness matrix

If the laminate is symmetrical the $[B]=0$ then

Bending stiffness matrix $[D]$

$D_{i j}=\frac{1}{3} \sum_{k=1}^{n}\left[Q_{i j}\right]_{k}\left(h_{k}^{3}-h_{k-1}^{3}\right), i=1,2,6 ; j=1,2,6=$ Bending

stiffness matrix

$$
\begin{aligned}
& {[D]=1 / 3\left[\begin{array}{ccc}
134.633 \times 10^{9} & 2.11 \times 10^{9} & 0 \\
2.11 \times 10^{9} & 7.033 \times 10^{9} & 0 \\
0 & 0 & 5.80 \times 10^{9}
\end{array}\right] \times 10^{9 \mathrm{pa}}{ }_{(2.1)^{3}-(-0.714)^{3}}^{3}} \\
& +1 / 3\left[\begin{array}{ccc}
7.033 \times 10^{9} & 2.11 \times 10^{9} & 0 \\
2.11 \times 10^{9} & 134.63 \times 10^{9} & 0 \\
0 & 0 & 5.80 \times 10^{9}
\end{array}\right] \times 10_{(-1.4)^{9}-(0.714)^{3}+}^{3}+
\end{aligned}
$$

$$
1 / 3\left[\begin{array}{ccc}
65.63 \times 10^{9} & 137 \times 10^{9} & 29.49 \times 10^{9} \\
137 \times 10^{9} & 40.6 \times 10^{9} & 29.49 \times 10^{9} \\
29.49 \times 10^{9} & 29.49 \times 10^{9} & 35.785 \times 10^{9}
\end{array}\right] \times 10_{(-2.1)^{9 p a}-(-1.4)}^{3}+
$$

$$
\begin{gathered}
1 / 3\left[\begin{array}{ccc}
65.63 \times 10^{9} & 137 \times 10^{9} & -29.45 \times 10^{9} \\
137 \times 10^{9} & 40.6 \times 10^{9} & -29.45 \times 10^{9} \\
-29.49 \times 10^{9} & 29.49 \times 10^{9} & 35.785 \times 10^{9}
\end{array}\right] \times 10^{9 \mathrm{pa}(1.4) 3-(-2.1) 3} \\
{[\mathrm{D}]=\left[\begin{array}{ccc}
543.297 \times 10^{9} & 251.26 \times 10^{9} & -182.68 \times 10^{9} \\
251.26 \times 10^{9} & -38.97 \times 10^{9} & -182.68 \times 10^{9} \\
-182.68 \times 10^{9} & 52.92 \times 10^{9} & 64.413 \times 10^{9}
\end{array}\right] \mathrm{pa}}
\end{gathered}
$$

Calculating mid-plane strain and stress

$$
\begin{aligned}
& {\left[\begin{array}{l}
N_{x} \\
N_{y} \\
N_{x y}
\end{array}\right]=\left[\begin{array}{llllll}
A_{11} & A_{12} & A 16 & B 11 & B 12 & B 16 \\
A_{12} & A_{22} & A 26 & B 12 & B 22 & B 26 \\
A 16 & A 26 & A_{66} B 16 & B 26 & B 66
\end{array}\right]\left[\begin{array}{c}
\varepsilon_{x}^{0} \\
\varepsilon_{y}^{0} \\
\gamma_{x y}^{0}
\end{array}\right]} \\
& {\left[\begin{array}{c}
M_{x} \\
M_{y} \\
M x y
\end{array}\right]=\left[\begin{array}{ccc}
B 11 B 12 B 16 D_{11} & D_{12} & D 16 \\
B 12 B 22 B 26 D_{12} & D_{22} & D 26 \\
B 16 B 26 B 66 D 16 & D 26 & D_{66}
\end{array}\right]\left[\begin{array}{c}
k_{x} o \\
k_{y} o \\
k x y o
\end{array}\right]}
\end{aligned}
$$

\section{Load deformation of moment of laminates}

For symmetric laminates, the B matrix vanishes and the in plane and bending stiffness are uncoupled. For a symmetric laminate, assume that the force is applied only on transverse direction of dead centre support, i.e., compression force on the $y$-axis.

$$
\left[\begin{array}{l}
N_{x} \\
N_{y} \\
N_{x y}
\end{array}\right]=\left[\begin{array}{ccc}
A_{11} & A_{12} & 0 \\
A_{12} & A_{22} & 0 \\
0 & 0 & A_{66}
\end{array}\right]\left[\begin{array}{l}
\varepsilon_{x}^{0} \\
\varepsilon_{y}^{0} \\
\gamma_{s}^{0}
\end{array}\right]
$$

$\mathrm{N}_{\mathrm{x}}, \mathrm{N}_{\mathrm{y}}=$ Normal force per unit length

$\mathrm{N}_{\mathrm{xy}}=$ Shear force per unit length $\mathrm{N} / \mathrm{m}$

$N x y=\frac{T}{2 x \pi x r^{2}}=50.7 \times 103 / 2 \times 3.14 \mathrm{x}(0.022 \mathrm{~m}) 2=166.803 \times 103$

$N_{x y}=\frac{F_{y}}{L}=166803 \mathrm{~N} / \mathrm{m}$, the length Dead centre support is $=400$ $\mathrm{mm}=0.4 \mathrm{~m}$

$$
\left[\begin{array}{c}
0 \\
166.803 \times 103 \\
0
\end{array}\right]=
$$

$\left.\begin{array}{lrr}547.76 \times 10^{9} & 385.1 \times 10^{9} & -123.743 \times 10^{9} \\ 385.1 \times 10^{9} & -151.14 \times 10^{9} & -123.743 \times 10^{9} \\ -123.743 \times 10^{9} & 123.743 \times 10^{9} & 104.26 \times 10^{9}\end{array}\right]\left[\begin{array}{l}\varepsilon_{x}^{0} \\ \varepsilon_{y}^{0} \\ \gamma_{s}^{0}\end{array}\right]$

$547.76 \times 10^{90}{ }_{x}+385.1 \times 10^{90}{ }_{y+}-123.743 \times 10^{90}{ }_{s}=0$

$385.1 \times 10^{90}{ }_{x}+-151.14 \times 10^{90}{ }_{y}+-123.743 \times 10^{90}{ }_{s}=166.803 \times 103$

$-123.743 \times 10^{90}+123.743 \times 10^{90}{ }_{y}+104.26 \times 10^{90}{ }_{s}=0$

After evaluating the simultaneous equation, the mid-plane strain is:

$\varepsilon_{x}^{0}=0.687 \times 10^{-6}$

$\varepsilon_{y}^{0}=-0.52 \times 10^{-6}$ 


$$
\begin{aligned}
& \gamma_{s}^{0}=1.43 \times 10^{-6} \\
& {\left[\begin{array}{l}
\varepsilon_{x}^{0} \\
\varepsilon_{y}^{0} \\
\gamma_{s}^{0}
\end{array}\right]=\left[\begin{array}{c}
0.687 \times 10^{-6} \\
-0.52 \times 10^{-6} \\
1.43 \times 10^{-6}
\end{array}\right]}
\end{aligned}
$$

When the Dead center support is subjected to torque $\tau$, the resultant forces in the laminate by considering the effect of centrifugal forces are: $\mathrm{Nx}=0, \mathrm{~N}_{\mathrm{Y}=}$ force applied on the Arbor $=\mathrm{N}_{\mathrm{xy}} \mathrm{L}=166803 \mathrm{~N} / \mathrm{m} \times$ $0.4 \mathrm{~m}=66.721 \times 10^{3}$.

\section{Calculating curvature}

$$
\left[\begin{array}{l}
M_{x} \\
M_{y} \\
M_{x y}
\end{array}\right]=\left[\begin{array}{ccc}
D_{11} & D_{12} & 0 \\
D_{12} & D_{22} & 0 \\
0 & 0 & D_{66}
\end{array}\right]\left[\begin{array}{l}
k_{x} \\
k_{y} \\
k_{x y}
\end{array}\right]
$$

$\mathrm{M}_{\mathrm{x}}, \mathrm{M}_{\mathrm{y}}=$ Bending moment per unit length

$\mathrm{M}_{\mathrm{xy}}=$ Twisting moment per unit length

In the practical machining process as we know that, there is only bending moment on the $\mathrm{x}$ - axis, i.e, $\mathrm{M}_{\mathrm{x}}$

Since $M=\left(F_{y} \frac{0.688}{2}\right) / L=\mathrm{N}\left(\frac{1.5}{2}\right) / L=66721 \times 0.688 / 2 \times$ $0.4=57.38 \times 10^{3}=\mathrm{M}_{\mathrm{x}}$

$$
\left[\begin{array}{c}
57380 \\
0 \\
0
\end{array}\right]=\left[\left[\begin{array}{ccc}
543.297 \times 10^{9} & 251.26 \times 10^{9} & -182.68 \times 10^{9} \\
251.26 \times 10^{9} & -38.97 \times 10^{9} & -182.68 \times 10^{9} \\
-182.68 \times 10^{9} & 52.92 \times 10^{9} & 64.413 \times 10^{9}
\end{array}\right]\right]\left[\begin{array}{c}
k_{x} \\
k_{y} \\
k_{x y}
\end{array}\right]
$$

From the above matrixes the three values of curvature is found as follows.

$$
\begin{aligned}
& 543.297 \times 10^{9} \mathrm{k}_{\mathrm{x}}+251.26 \times 10^{9} \mathrm{~K}_{\mathrm{y}}+-182.68 \times 10^{9} \mathrm{~K}_{\mathrm{xy}}=57380 \\
& 251.26 \times 10^{9} \mathrm{k}_{\mathrm{x}}+-38.97 \times 10^{9} \mathrm{~K}_{\mathrm{y}}+-182.68 \times 10^{9} \mathrm{~K}_{\mathrm{xy}}=0 \\
& -182.68 \times 10^{9} \mathrm{k}_{\mathrm{x}}+52.92 \times 10^{9} \mathrm{~K}_{\mathrm{y}}+64.413 \times 10^{9} \mathrm{~K}_{\mathrm{xy}}=0
\end{aligned}
$$

After evaluating the simultaneous equation, the curvature is:

$$
\left[\begin{array}{l}
k_{x} \\
k_{y} \\
k_{x y}
\end{array}\right]=\left[\begin{array}{c}
0 \\
196.76 \\
-41.81
\end{array}\right] X 10^{-9}
$$

\section{Hydrothermal stresses and strains}

Most polymeric matrix composites can absorb or reabsorb moisture. This moisture change leads to swelling strains and stresses similar to those due to thermal expansion. Laminates in which laminate are placed at different angles have residual stresses in each lamina due to differing Hydrothermal expansion of each lamina [9]. The Hydrothermal strains are not equal in a lamina in the longitudinal and transverse directions because the elastic constants and the thermal and moisture expansion coefficients of the fibber and matrix are different. In the following sections, stress strain relationships are developed for unidirectional and angle lamina subjected to Hydrothermal loads. Assume that tailstock dead centre support is performed in a climate with the range of $15^{\circ} \mathrm{C}-65^{\circ} \mathrm{C}$ and the moisture Absorption of $0.02 \mathrm{~kg} /$ $\mathrm{kg}$. The terms ax, ay and axy are the coefficients of thermal expansion for an angle lamina and are given in terms of the coefficients of thermal expansion for a unidirectional lamina as:

$$
\left[\begin{array}{l}
\alpha_{x} \\
\alpha_{y} \\
\alpha_{x y}
\end{array}\right]=T^{-1}\left[\begin{array}{c}
\alpha_{1} \\
\alpha_{2} \\
0
\end{array}\right]
$$

Similarly, $\beta \mathrm{x}, \beta \mathrm{y}$, and $\beta \mathrm{xy}$ are the coefficients of moisture expansion for an angle lamina and are given in terms of the coefficients of moisture expansion for a unidirectional lamina as:

$$
\left[\begin{array}{l}
\beta_{x} \\
\beta_{y} \\
\beta_{x y}
\end{array}\right]=T^{-1}\left[\begin{array}{c}
\beta_{1} \\
\beta_{2} \\
0
\end{array}\right] \text { and }
$$

Local strains due to Hydrothermal are calculated as:

$$
\left[\begin{array}{c}
\varepsilon_{x} \\
\varepsilon_{y} \\
\varepsilon_{x y}
\end{array}\right]=\Delta T T^{-1}\left[\begin{array}{c}
\alpha_{1} \\
\alpha_{2} \\
0
\end{array}\right]+\Delta m T^{-1}\left[\begin{array}{c}
\beta_{1} \\
\beta_{2} \\
0
\end{array}\right]
$$

Where,

$\Delta \mathrm{T}=$ change in temperature

$\alpha_{1}, \alpha_{2=}$ longitudinal and transversal thermal expansion

$\Delta \mathrm{m}=$ weight of observation per unit of lamina

$\beta_{1}, \beta_{2}=$ longitudinal and transversal coefficient of moisture

$\Delta \mathrm{T}=65^{\circ} \mathrm{C}-15^{\circ} \mathrm{C}=50^{\circ} \mathrm{C}$

Using the above formulas the hydrothermal of the in the given products were tested in the next part.

\section{For carbon/epoxy}

$\alpha_{1}=-0.9 \times 10^{-66 \mathrm{~m} / \mathrm{m} / 0 \mathrm{c}}, \alpha_{2}=30.6 \times 10^{-6 \mathrm{~m} / \mathrm{m} / 0 \mathrm{c}}$

$\beta_{1}=0.01 \mathrm{~m} / \mathrm{m} / \mathrm{kg} / \mathrm{kg}, \beta_{2=} 0.2 \mathrm{~m} / \mathrm{m} / \mathrm{kg} / \mathrm{kg}$

$\left[\begin{array}{l}\varepsilon_{x} \\ \varepsilon_{y} \\ \varepsilon_{x y}\end{array}\right]=\Delta T\left[\begin{array}{ccc}M^{2} & N^{2} & -M N \\ N^{2} & M^{2} & N M \\ 2 N M & -2 M N & M^{2}-N^{2}\end{array}\right]\left[\begin{array}{c}\alpha_{1} \\ \alpha_{2} \\ 0\end{array}\right]+\Delta C\left[\begin{array}{ccc}M^{2} & N^{2} & -M N \\ N^{2} & M^{2} & N M \\ 2 N M & -2 M N & M^{2}-N^{2}\end{array}\right]\left[\begin{array}{c}\beta_{1} \\ \beta_{2} \\ 0\end{array}\right]$

For $0^{\circ}$ angle at the top

$\left[\begin{array}{c}\varepsilon_{x} \\ \varepsilon_{y} \\ \varepsilon_{x y}\end{array}\right]=\Delta T\left[\begin{array}{ccc}M^{2} & N^{2} & -M N \\ N^{2} & M^{2} & N M \\ 2 N M & -2 M N & M^{2}-N^{2}\end{array}\right]\left[\begin{array}{c}\alpha_{1} \\ \alpha_{2} \\ 0\end{array}\right]+\Delta C\left[\begin{array}{ccc}M^{2} & N^{2} & -M N \\ N^{2} & M^{2} & N M \\ 2 N M & -2 M N & M^{2}-N^{2}\end{array}\right]\left[\begin{array}{c}\beta_{1} \\ \beta_{2} \\ 0\end{array}\right]$

$\left[\begin{array}{l}\varepsilon_{x} \\ \varepsilon_{y} \\ \varepsilon_{x y}\end{array}\right]=50\left[\begin{array}{lll}1 & 0 & 0 \\ 0 & 1 & 0 \\ 0 & 0 & 1\end{array}\right]\left[\begin{array}{c}-0.9 \times 10^{-6} \\ 30.6 \times 10^{-6} \\ 0\end{array}\right]+0.02\left[\begin{array}{ccc}1 & 0 & 0 \\ 0 & 1 & 0 \\ 0 & 0 & 1\end{array}\right]\left[\begin{array}{c}0.01 \\ 0.2 \\ 0\end{array}\right]$

$\left[\begin{array}{l}\varepsilon_{x} \\ \varepsilon_{y} \\ \varepsilon_{x y}\end{array}\right]=\left[\begin{array}{c}155 \times 10^{-6} \\ 5530 \times 10^{-6} \\ 0\end{array}\right]$

At $90^{\circ}$ 
$\left[\begin{array}{c}\varepsilon_{x} \\ \varepsilon_{y} \\ \varepsilon_{x y}\end{array}\right]=50\left[\begin{array}{ccc}0 & 1 & 0 \\ 1 & 0 & 0 \\ 0 & 0 & -1\end{array}\right]\left[\begin{array}{c}-0.9 \times 10^{-6} \\ 30.6 \times 10^{-6} \\ 0\end{array}\right]+0.02\left[\begin{array}{ccc}0 & 1 & 0 \\ 1 & 0 & 0 \\ 0 & 0 & -1\end{array}\right]\left[\begin{array}{c}0.01 \\ 0.2 \\ 0\end{array}\right]$

$$
\left[\begin{array}{l}
\varepsilon_{x} \\
\varepsilon_{y} \\
\varepsilon_{x y}
\end{array}\right]=\left[\begin{array}{c}
5530 \times 10^{-6} \\
155 \times 10^{-6} \\
0
\end{array}\right]
$$

At $45^{\circ}$

$\left[\begin{array}{l}\varepsilon_{x} \\ \varepsilon_{y} \\ \varepsilon_{x y}\end{array}\right]=50\left[\begin{array}{ccc}0.5 & 0.5 & -0.5 \\ 0.5 & 0.5 & 0.5 \\ 1 & -1 & 0\end{array}\right]\left[\begin{array}{c}-0.9 x 10^{-6} \\ 30.6 x 10^{-6} \\ 0\end{array}\right]+0.02\left[\begin{array}{ccc}0.5 & 0.5 & -0.5 \\ 0.5 & 0.5 & 0.5 \\ 1 & -1 & 0\end{array}\right]\left[\begin{array}{c}0.01 \\ 0.2 \\ 0\end{array}\right]$

$$
\left[\begin{array}{l}
\varepsilon_{x} \\
\varepsilon_{y} \\
\varepsilon_{x y}
\end{array}\right]=\left[\begin{array}{c}
2842.5 \times 10^{-6} \\
2842.5 \times 10^{-6} \\
-5375 \times 10^{-6}
\end{array}\right]
$$

At $-45^{\circ}$

$\left[\begin{array}{l}\varepsilon_{x} \\ \varepsilon_{y} \\ \varepsilon_{x y}\end{array}\right]=50\left[\begin{array}{ccc}0.5 & 0.5 & 0.5 \\ 0.5 & 0.5 & -0.5 \\ -1 & 1 & 0\end{array}\right]\left[\begin{array}{c}-0.9 x 10^{-6} \\ 30.6 x 10^{-6} \\ 0\end{array}\right]+0.02\left[\begin{array}{ccc}0.5 & 0.5 & 0.5 \\ 0.5 & 0.5 & -0.5 \\ -1 & 1 & 0\end{array}\right]\left[\begin{array}{c}0.01 \\ 0.2 \\ 0\end{array}\right]$

$$
\left[\begin{array}{c}
\varepsilon_{x} \\
\varepsilon_{y} \\
\varepsilon_{x y}
\end{array}\right]=\left[\begin{array}{c}
2842.5 \times 10^{-6} \\
2842.5 \times 10^{-6} \\
5375 \times 10^{-6}
\end{array}\right]
$$

Global strain and stresses

$$
\left[\begin{array}{c}
\varepsilon_{x} \\
\varepsilon_{y} \\
\varepsilon_{x y}
\end{array}\right] \text { At } k \text { layer }=\left[\begin{array}{l}
0 \\
x \\
0 \\
y \\
0 \\
s
\end{array}\right]+z\left[\begin{array}{l}
k_{x} \\
k_{y} \\
k_{s}
\end{array}\right]+\left[\begin{array}{c}
\varepsilon_{x} \\
\varepsilon_{y} \\
\varepsilon_{x y}
\end{array}\right]
$$

Global strain and stresses at $0^{\circ}$ for $0.714 \mathrm{~mm}$ high

$$
\left[\begin{array}{c}
\varepsilon_{x} \\
\varepsilon_{y} \\
\varepsilon_{x y}
\end{array}\right] 0^{\circ}=\left[\left[\begin{array}{c}
0.687 X 10^{-6} \\
-0.52 X 10^{-6} \\
1.43 \times 10^{-6}
\end{array}\right]\right]+0.714\left[\left[\begin{array}{c}
0 \\
196.76 \\
-41.81
\end{array}\right] X 10^{-9}\right]+
$$

$$
\begin{aligned}
& \left.\left[\begin{array}{c}
155 \times 10^{-6} \\
5530 \times 10^{-6} \\
0
\end{array}\right]\right] \\
& \text { Thus }\left[\begin{array}{l}
\varepsilon_{x} \\
\varepsilon_{y} \\
\varepsilon_{x y}
\end{array}\right]=\left[\begin{array}{c}
155.76 \times 10^{-6} \\
5529.48 \times 10^{-6} \\
1.4 \times 10^{-6}
\end{array}\right] \\
& {\left[\begin{array}{l}
\sigma_{x} \\
\sigma_{y} \\
\tau_{x y}
\end{array}\right]=\left[\begin{array}{ccc}
\bar{Q}_{11} & \bar{Q}_{12} & 0 \\
\bar{Q}_{12} & \bar{Q}_{22} & 0 \\
0 & 0 & \bar{Q}_{66}
\end{array}\right]\left[\begin{array}{l}
\varepsilon_{x} \\
\varepsilon_{y} \\
\varepsilon_{x y}
\end{array}\right]}
\end{aligned}
$$

$\left[\begin{array}{c}\sigma_{x} \\ \sigma_{y} \\ \tau_{x y}\end{array}\right]=\left[\begin{array}{ccc}134.633 \times 10^{9} & 2.11 \times 10^{9} & 0 \\ 2.11 \times 10^{9} & 7.033 \times 10^{9} & 0 \\ 0 & 0 & 5.80 \times 10^{9}\end{array}\right]$ pa $\left[\begin{array}{c}155.76 \times 10^{-6} \\ 5529.48 \times 10^{-6} \\ 1.4 \times 10^{-6}\end{array}\right]$

Finally,

$$
\left[\begin{array}{c}
\sigma_{x} \\
\sigma_{y} \\
\tau_{x y}
\end{array}\right]=\left[\begin{array}{c}
32.64 \\
39.22 \\
0.00812
\end{array}\right] X 10^{6} \mathrm{pa}
$$

\section{Local strain and stresses}

$\left[\begin{array}{c}\varepsilon_{1} \\ \varepsilon_{2} \\ \gamma_{12}\end{array}\right]$ at $0^{\circ}=\left[\begin{array}{ccc}M^{2} & N^{2} & -M N \\ N^{2} & M^{2} & N M \\ 2 N M & -2 M N & M^{2}-N^{2}\end{array}\right]\left[\begin{array}{l}\varepsilon_{x} \\ \varepsilon_{x} \\ \gamma_{s}\end{array}\right]$

Since $\left[\begin{array}{l}\varepsilon_{1} \\ \varepsilon_{2} \\ \gamma_{s}\end{array}\right]=\left[\begin{array}{lll}1 & 0 & 0 \\ 0 & 1 & 0 \\ 0 & 0 & 1\end{array}\right]\left[\left[\begin{array}{c}155.76 \times 10^{-6} \\ 5529.48 \times 10^{-6} \\ 1.4 \times 10^{-6}\end{array}\right]\right]$

$\left[\begin{array}{l}\varepsilon_{1} \\ \varepsilon_{2} \\ \gamma_{s}\end{array}\right]=\left[\begin{array}{c}155.76 \times 10^{-6} \\ 5529.48 \times 10^{-6} \\ 1.4 \times 10^{-6}\end{array}\right]$

$\left[\begin{array}{c}\sigma_{1} \\ \sigma_{2} \\ \tau_{12}\end{array}\right] \operatorname{Top} 0^{\circ}=\left[\begin{array}{ccc}M^{2} & N^{2} & -M N \\ N^{2} & M^{2} & N M \\ 2 N M & -2 M N & M^{2}-N^{2}\end{array}\right]\left[\begin{array}{c}\sigma_{x} \\ \sigma_{x} \\ \gamma_{x y}\end{array}\right]$

$\left[\begin{array}{c}\sigma_{1} \\ \sigma_{2} \\ \tau_{12}\end{array}\right]=\left[\begin{array}{lll}1 & 0 & 0 \\ 0 & 1 & 0 \\ 0 & 0 & 1\end{array}\right]\left[\left[\begin{array}{c}32.64 \\ 39.22 \\ 0.00812\end{array}\right]\right] X 10^{6} \mathrm{pa}$

$\left[\begin{array}{c}\sigma_{1} \\ \sigma_{2} \\ \tau_{12}\end{array}\right]=\left[\left[\begin{array}{c}32.64 \\ 39.22 \\ 0.00812\end{array}\right]\right] X 106$

Global strain and stresses at the bottom of $0^{\circ}$ at $-0.714 \mathrm{~mm}$

$\left[\begin{array}{l}\varepsilon_{x} \\ \varepsilon_{y} \\ \varepsilon_{x y}\end{array}\right] 0^{\circ}=\left[\left[\begin{array}{c}0.687 \times 10^{-6} \\ -0.52 \times 10^{-6} \\ 1.43 \times 10^{-6}\end{array}\right]\right]+-0.714\left[\left[\begin{array}{c}0 \\ 196.76 \\ -41.81\end{array}\right] \times 10^{-9}\right]+\left[\left[\begin{array}{c}155 \times 10^{-6} \\ 5530 \times 10^{-6} \\ 0\end{array}\right]\right]$

$\left[\begin{array}{l}\varepsilon_{x} \\ \varepsilon_{y} \\ \varepsilon_{x y}\end{array}\right]=\left[\begin{array}{c}155.688 \times 10^{-6} \\ 5529.3 \times 10^{-6} \\ 1.46 \times 10^{-6}\end{array}\right]$

$\left[\begin{array}{c}\sigma_{x} \\ \sigma_{y} \\ \tau_{x y}\end{array}\right]=\left[\begin{array}{ccc}\bar{Q}_{11} & \bar{Q}_{12} & 0 \\ \bar{Q}_{12} & \bar{Q}_{22} & 0 \\ 0 & 0 & \bar{Q}_{66}\end{array}\right]\left[\begin{array}{c}\varepsilon_{x} \\ \varepsilon_{y} \\ \varepsilon_{x y}\end{array}\right]$ 
$\left[\begin{array}{c}\sigma_{x} \\ \sigma_{y} \\ \tau_{x y}\end{array}\right]=\left[\begin{array}{ccc}134.633 \times 10^{9} & 2.11 \times 10^{9} & 0 \\ 2.11 \times 10^{9} & 7.033 \times 10^{9} & 0 \\ 0 & 0 & 5.80 \times 10^{9}\end{array}\right] X 10^{9} \mathrm{pa}$

$\left[\left[\begin{array}{c}155.688 \times 10^{-6} \\ 5529.3 \times 10^{-6} \\ 1.46 \times 10^{-6}\end{array}\right]\right]$

$\left[\begin{array}{l}\sigma_{x} \\ \sigma_{y} \\ \tau_{x y}\end{array}\right]=\left[\begin{array}{c}32.64 \\ 39.22 \\ 0.00812\end{array}\right] X 10^{6} \mathrm{pa}$

Global strain and stresses at $45^{\circ}$ for $-1.4 \mathrm{~mm}$

$\left[\begin{array}{l}\varepsilon_{x} \\ \varepsilon_{y} \\ \varepsilon_{x y}\end{array}\right] 45^{\circ}=\left[\left[\begin{array}{c}0.687 \times 10^{-6}, \\ -0.52 \times 10^{-6} \\ 1.43 \times 10^{-6}\end{array}\right]\right]+-1.4\left[\left[\begin{array}{c}0 \\ 196.76 \\ -41.81\end{array}\right] X 10^{-9}\right]+$

$\left[\left[\begin{array}{c}155 \times 10^{-6} \\ 5530 \times 10^{-6} \\ 0\end{array}\right]\right]$

$\left[\begin{array}{l}\varepsilon_{x} \\ \varepsilon_{y} \\ \varepsilon_{x y}\end{array}\right]=\left[\begin{array}{c}155.76 \times 10^{-6} \\ 5529.2 \times 10^{-6} \\ 1.488 \times 10^{-6}\end{array}\right]$

$\left[\begin{array}{c}\sigma_{x} \\ \sigma_{y} \\ \tau_{x y}\end{array}\right]=\left[\begin{array}{ccc}\bar{Q}_{11} & \bar{Q}_{12} & 0 \\ \bar{Q}_{12} & \bar{Q}_{22} & 0 \\ 0 & 0 & \bar{Q}_{66}\end{array}\right]\left[\begin{array}{c}\varepsilon_{x} \\ \varepsilon_{y} \\ \varepsilon_{x y}\end{array}\right]$

$\left[\begin{array}{l}\sigma_{x} \\ \sigma_{y} \\ \tau_{x y}\end{array}\right]=\left[\begin{array}{ccc}134.633 \times 10^{9} & 2.11 \times 10^{9} & 0 \\ 2.11 \times 10^{9} & 7.033 \times 10^{9} & 0 \\ 0 & 0 & 5.80 \times 10^{9}\end{array}\right] \mathrm{pa}$

$$
\begin{aligned}
& {\left[\begin{array}{c}
155.76 \times 10^{-6} \\
5529.2 \times 10^{-6} \\
1.488 \times 10^{-6}
\end{array}\right]} \\
& {\left[\begin{array}{l}
\sigma_{x} \\
\sigma_{y} \\
\tau_{x y}
\end{array}\right]=\left[\begin{array}{c}
32.63 \\
39.2 \\
0.00863
\end{array}\right] X 10^{6} \mathrm{pa}}
\end{aligned}
$$

Local strain and stresses At $45^{\circ}$

$$
\left[\begin{array}{c}
\varepsilon_{1} \\
\varepsilon_{2} \\
\gamma_{12}
\end{array}\right] \text { At } 45^{\circ}=\left[\begin{array}{ccc}
M^{2} & N^{2} & -M N \\
N^{2} & M^{2} & N M \\
2 N M & -2 M N & M^{2}-N^{2}
\end{array}\right]\left[\begin{array}{l}
\varepsilon_{x} \\
\varepsilon_{x} \\
\gamma_{s}
\end{array}\right]
$$

$\left[\begin{array}{l}\varepsilon_{1} \\ \varepsilon_{2} \\ \gamma_{s}\end{array}\right]=\left[\begin{array}{ccc}0.5 & 0.5 & -0.5 \\ 0.5 & 0.5 & 0.5 \\ 1 & -1 & 0\end{array}\right]\left[\left[\begin{array}{c}155.76 \times 10^{-6} \\ 5529.2 \times 10^{-6} \\ 1.488 \times 10^{-6}\end{array}\right]\right]$

$\left[\begin{array}{l}\varepsilon_{1} \\ \varepsilon_{2} \\ \gamma_{s}\end{array}\right]=\left[\begin{array}{c}2.841 \times 10^{-3} \\ 2.843 \times 10^{-3} \\ -5.373 \times 10^{-3}\end{array}\right]$

$\left[\begin{array}{c}\sigma_{1} \\ \sigma_{2} \\ \tau_{12}\end{array}\right]=\left[\begin{array}{ccc}M^{2} & N^{2} & -M N \\ N^{2} & M^{2} & N M \\ 2 N M & -2 M N & M^{2}-N^{2}\end{array}\right]\left[\begin{array}{c}\sigma_{x} \\ \sigma_{x} \\ \gamma_{x y}\end{array}\right]$

$\left[\begin{array}{l}\sigma_{1} \\ \sigma_{2} \\ \tau_{12}\end{array}\right]=\left[\begin{array}{ccc}0.5 & 0.5 & -0.5 \\ 0.5 & 0.5 & 0.5 \\ 1 & -1 & 0\end{array}\right]\left[\left[\begin{array}{c}32.63 \\ 39.2 \\ 0.00863\end{array}\right]\right] X 10^{6} \mathrm{pa}$

$\left[\begin{array}{l}\sigma_{1} \\ \sigma_{2} \\ \tau_{12}\end{array}\right]=\left[\left[\begin{array}{c}35.91 \\ 35.91 \\ -6.57\end{array}\right]\right] X 106$

Global strain and stresses at $-45^{\circ}$ degree for $1.4 \mathrm{~mm}$

$\left[\begin{array}{c}\varepsilon_{x} \\ \varepsilon_{y} \\ \varepsilon_{x y}\end{array}\right] \quad 45^{\circ}=\left[\left[\begin{array}{c}0.687 \times 10^{-6}, \\ -0.52 \times 10^{-6} \\ 1.43 \times 10^{-6}\end{array}\right]\right]+1.4\left[\left[\begin{array}{c}0 \\ 196.76 \\ -41.81\end{array}\right] X 10^{-9}\right]+$

$\left[\left[\begin{array}{c}155 \times 10^{-6} \\ 5530 \times 10^{-6} \\ 0\end{array}\right]\right]$

$\left[\begin{array}{l}\varepsilon_{x} \\ \varepsilon_{y} \\ \varepsilon_{x y}\end{array}\right]=\left[\begin{array}{c}155.76 \times 10^{-6} \\ 5529.76 \times 10^{-6} \\ 1.34 \times 10^{-6}\end{array}\right]$

$\left[\begin{array}{c}\sigma_{x} \\ \sigma_{y} \\ \tau_{x y}\end{array}\right]=\left[\begin{array}{ccc}\bar{Q}_{11} & \bar{Q}_{12} & 0 \\ \bar{Q}_{12} & \bar{Q}_{22} & 0 \\ 0 & 0 & \bar{Q}_{66}\end{array}\right]\left[\begin{array}{c}\varepsilon_{x} \\ \varepsilon_{y} \\ \varepsilon_{x y}\end{array}\right]$

$\left[\begin{array}{l}\sigma_{x} \\ \sigma_{y} \\ \tau_{x y}\end{array}\right]=\left[\begin{array}{ccc}134.633 \times 10^{9} & 2.11 \times 10^{9} & 0 \\ 2.11 \times 10^{9} & 7.033 \times 10^{9} & 0 \\ 0 & 0 & 5.80 \times 10^{9}\end{array}\right] \mathrm{pa}$

$\left[\begin{array}{c}155.76 \times 10^{-6} \\ 5529.76 \times 10^{-6} \\ 1.34 \times 10^{-6}\end{array}\right]$ 
Ultimately $\left[\begin{array}{c}\sigma_{x} \\ \sigma_{y} \\ \tau_{x y}\end{array}\right]=\left[\begin{array}{c}32.63 \\ 39.763 \\ 0.00813\end{array}\right] X_{10} \mathrm{pa}$

Local strain and stresses at $-45^{\circ}$

$\left[\begin{array}{c}\varepsilon_{1} \\ \varepsilon_{2} \\ \gamma_{12}\end{array}\right]$ At $-45^{\circ}=\left[\begin{array}{ccc}M^{2} & N^{2} & -M N \\ N^{2} & M^{2} & N M \\ 2 N M & -2 M N & M^{2}-N^{2}\end{array}\right]\left[\begin{array}{l}\varepsilon_{x} \\ \varepsilon_{x} \\ \gamma_{s}\end{array}\right]$

$\left[\begin{array}{l}\varepsilon_{1} \\ \varepsilon_{2} \\ \gamma_{s}\end{array}\right]=\left[\begin{array}{ccc}0.5 & 0.5 & 0.5 \\ 0.5 & 0.5 & -0.5 \\ -1 & 1 & 0\end{array}\right]\left[\left[\begin{array}{c}155.76 \times 10^{-6} \\ 5529.76 \times 10^{-6} \\ 1.34 \times 10^{-6}\end{array}\right]\right]$

The final result is $\left[\begin{array}{l}\varepsilon_{1} \\ \varepsilon_{2} \\ \gamma_{s}\end{array}\right]=\left[\begin{array}{l}2.843 \times 10^{-3} \\ 2.841 \times 10^{-3} \\ 5.373 \times 10^{-3}\end{array}\right]$

$\left[\begin{array}{c}\sigma_{1} \\ \sigma_{2} \\ \tau_{12}\end{array}\right]=\left[\begin{array}{ccc}M^{2} & N^{2} & -M N \\ N^{2} & M^{2} & N M \\ 2 N M & -2 M N & M^{2}-N^{2}\end{array}\right]\left[\begin{array}{c}\sigma_{x} \\ \sigma_{x} \\ \gamma_{x y}\end{array}\right]$

$\left[\begin{array}{c}\sigma_{1} \\ \sigma_{2} \\ \tau_{12}\end{array}\right]=\left[\begin{array}{ccc}0.5 & 0.5 & 0.5 \\ 0.5 & 0.5 & -0.5 \\ -1 & 1 & 0\end{array}\right]\left[\left[\begin{array}{c}32.63 \\ 39.763 \\ 0.00813\end{array}\right]\right] X 10^{6} \mathrm{pa}$

$\left[\begin{array}{c}\sigma_{1} \\ \sigma_{2} \\ \tau_{12}\end{array}\right]=\left[\left[\begin{array}{c}36.20 \\ 16.23 \\ 7.13\end{array}\right]\right] X 106$

Global strain and stresses at $90^{\circ}$ degree for $2.1 \mathrm{~mm}$

$\left[\begin{array}{c}\varepsilon_{x} \\ \varepsilon_{y} \\ \varepsilon_{x y}\end{array}\right] 90^{\circ}=\left[\left[\begin{array}{c}0.687 X 10^{-6} \\ -0.52 X 10^{-6} \\ 1.43 X 10^{-6}\end{array}\right]\right]+2.1\left[\left[\begin{array}{c}0 \\ 196.76 \\ -41.81\end{array}\right] X 10^{-9}\right]+$

$\left[\left[\begin{array}{c}155 \times 10^{-6} \\ 5530 \times 10^{-6} \\ 0\end{array}\right]\right]$

$$
\begin{aligned}
& {\left[\begin{array}{c}
\varepsilon_{x} \\
\varepsilon_{y} \\
\varepsilon_{x y}
\end{array}\right]=\left[\begin{array}{c}
155.76 \times 10^{-6} \\
5529.89 \times 10^{-6} \\
1.34 \times 10^{-6}
\end{array}\right]} \\
& {\left[\begin{array}{c}
\sigma_{x} \\
\sigma_{y} \\
\tau_{x y}
\end{array}\right]=\left[\begin{array}{ccc}
\bar{Q}_{11} & \bar{Q}_{12} & 0 \\
\bar{Q}_{12} & \bar{Q}_{22} & 0 \\
0 & 0 & \bar{Q}_{66}
\end{array}\right]\left[\begin{array}{l}
\varepsilon_{x} \\
\varepsilon_{y} \\
\varepsilon_{x y}
\end{array}\right]}
\end{aligned}
$$

$$
\left[\begin{array}{c}
\sigma_{x} \\
\sigma_{y} \\
\tau_{x y}
\end{array}\right]=\left[\begin{array}{ccc}
134.633 \times 10^{9} & 2.11 \times 10^{9} & 0 \\
2.11 \times 10^{9} & 7.033 \times 10^{9} & 0 \\
0 & 0 & 5.80 \times 10^{9}
\end{array}\right]
$$

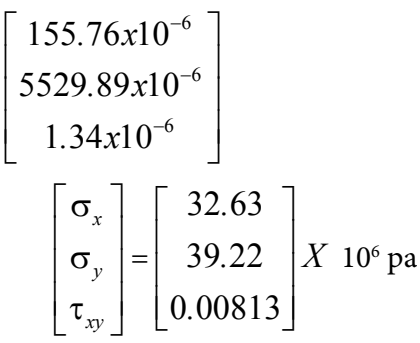

Local strain and stresses At $90^{\circ}$

$\left[\begin{array}{c}\varepsilon_{1} \\ \varepsilon_{2} \\ \gamma_{12}\end{array}\right]$ At $90^{\circ}=\left[\begin{array}{ccc}M^{2} & N^{2} & -M N \\ N^{2} & M^{2} & N M \\ 2 N M & -2 M N & M^{2}-N^{2}\end{array}\right]\left[\begin{array}{l}\varepsilon_{x} \\ \varepsilon_{x} \\ \gamma_{s}\end{array}\right]$

$\left[\begin{array}{l}\varepsilon_{1} \\ \varepsilon_{2} \\ \gamma_{s}\end{array}\right]=\left[\begin{array}{ccc}0 & 1 & 0 \\ 1 & 0 & 0 \\ 0 & 0 & -1\end{array}\right]\left[\left[\begin{array}{c}155.76 \times 10^{-6} \\ 5529.76 \times 10^{-6} \\ 1.34 \times 10^{-6}\end{array}\right]\right]$

$\left[\begin{array}{l}\varepsilon_{1} \\ \varepsilon_{2} \\ \gamma_{s}\end{array}\right]=\left[\begin{array}{c}5529.76 \times 10^{-6} \\ 155.76 \times 10^{-6} \\ -1.34 \times 10^{-6}\end{array}\right]$

$\left[\begin{array}{c}\sigma_{1} \\ \sigma_{2} \\ \tau_{12}\end{array}\right]=\left[\begin{array}{ccc}M^{2} & N^{2} & -M N \\ N^{2} & M^{2} & N M \\ 2 N M & -2 M N & M^{2}-N^{2}\end{array}\right]\left[\begin{array}{c}\sigma_{x} \\ \sigma_{x} \\ \gamma_{x y}\end{array}\right]$

$\left[\begin{array}{l}\sigma_{1} \\ \sigma_{2} \\ \tau_{12}\end{array}\right]=\left[\begin{array}{ccc}0 & 1 & 0 \\ 1 & 0 & 0 \\ 0 & 0 & -1\end{array}\right]\left[\left[\begin{array}{c}32.63 \\ 39.22 \\ 0.00813\end{array}\right]\right] X 10^{6} \mathrm{pa}$

$\left[\begin{array}{c}\sigma_{1} \\ \sigma_{2} \\ \tau_{12}\end{array}\right]=\left[\left[\begin{array}{c}39.22 \\ 32.63 \\ -0.00813\end{array}\right]\right] X 106$

Global strain and stresses at $90^{\circ}$ degree for $-2.1 \mathrm{~mm}$ $\left[\begin{array}{c}\varepsilon_{x} \\ \varepsilon_{y} \\ \varepsilon_{x y}\end{array}\right] \quad 90^{\circ}=\left[\left[\begin{array}{c}0.687 \times 10^{-6} \\ -0.52 \times 10^{-6} \\ 1.43 \times 10^{-6}\end{array}\right]\right]+\left(-2.1\left[\left[\begin{array}{c}0 \\ 196.76 \\ -41.81\end{array}\right] X 10^{-9}\right]+\right.$

$\left[\left[\begin{array}{c}155 \times 10^{-6} \\ 5530 \times 10^{-6} \\ 0\end{array}\right]\right]$ 
$\left[\begin{array}{l}\varepsilon_{x} \\ \varepsilon_{y} \\ \varepsilon_{x y}\end{array}\right]=\left[\begin{array}{c}155.76 \times 10^{-6} \\ 5529.07 \times 10^{-6} \\ 1.52 \times 10^{-6}\end{array}\right]$

$\left[\begin{array}{c}\sigma_{x} \\ \sigma_{y} \\ \tau_{x y}\end{array}\right]=\left[\begin{array}{ccc}\bar{Q}_{11} & \bar{Q}_{12} & 0 \\ \bar{Q}_{12} & \bar{Q}_{22} & 0 \\ 0 & 0 & \bar{Q}_{66}\end{array}\right]\left[\begin{array}{c}\varepsilon_{x} \\ \varepsilon_{y} \\ \varepsilon_{x y}\end{array}\right]$

$\left[\begin{array}{c}\sigma_{x} \\ \sigma_{y} \\ \tau_{x y}\end{array}\right]=\left[\begin{array}{crr}134.633 \times 10^{9} & 2.11 \times 10^{9} & 0 \\ 2.11 \times 10^{9} & 7.033 \times 10^{9} & 0 \\ 0 & 0 & 5.80 \times 10^{9}\end{array}\right] \mathrm{pa}$

$\left[\begin{array}{c}155.76 \times 10^{-6} \\ 5529.07 \times 10^{-6} \\ 1.52 \times 10^{-6}\end{array}\right]$

$\left[\begin{array}{c}\sigma_{x} \\ \sigma_{y} \\ \tau_{x y}\end{array}\right]=\left[\begin{array}{c}32.63 \\ 39.22 \\ 0.0088\end{array}\right] X 10^{6} \mathrm{pa}$

Local strain and stresses at $90^{\circ}$ for- $2.1 \mathrm{~mm}$

$\left[\begin{array}{c}\varepsilon_{1} \\ \varepsilon_{2} \\ \gamma_{12}\end{array}\right]$ At $90^{\circ}=\left[\begin{array}{ccc}M^{2} & N^{2} & -M N \\ N^{2} & M^{2} & N M \\ 2 N M & -2 M N & M^{2}-N^{2}\end{array}\right]\left[\begin{array}{l}\varepsilon_{x} \\ \varepsilon_{x} \\ \gamma_{s}\end{array}\right]$

$\left[\begin{array}{l}\varepsilon_{1} \\ \varepsilon_{2} \\ \gamma_{s}\end{array}\right]=\left[\begin{array}{ccc}0 & 1 & 0 \\ 1 & 0 & 0 \\ 0 & 0 & -1\end{array}\right]\left[\left[\begin{array}{c}155.76 \times 10^{-6} \\ 5529.07 \times 10^{-6} \\ 1.52 \times 10^{-6}\end{array}\right]\right]$

$\left[\begin{array}{l}\varepsilon_{1} \\ \varepsilon_{2} \\ \gamma_{s}\end{array}\right]=\left[\begin{array}{c}5529.07 \times 10^{-6} \\ 155.76 \times 10^{-6} \\ 1.52 \times 10^{-6}\end{array}\right]$

$\left[\begin{array}{c}\sigma_{1} \\ \sigma_{2} \\ \tau_{12}\end{array}\right]=\left[\begin{array}{ccc}M^{2} & N^{2} & -M N \\ N^{2} & M^{2} & N M \\ 2 N M & -2 M N & M^{2}-N^{2}\end{array}\right]\left[\begin{array}{c}\sigma_{x} \\ \sigma_{x} \\ \gamma_{x y}\end{array}\right]$

$\left[\begin{array}{c}\sigma_{1} \\ \sigma_{2} \\ \tau_{12}\end{array}\right]=\left[\begin{array}{ccc}0 & 1 & 0 \\ 1 & 0 & 0 \\ 0 & 0 & -1\end{array}\right]\left[\left[\begin{array}{c}32.63 \\ 39.22 \\ 0.0088\end{array}\right]\right] X 10^{6} \mathrm{pa}$

$\left[\begin{array}{c}\sigma_{1} \\ \sigma_{2} \\ \tau_{12}\end{array}\right]=\left[\left[\begin{array}{c}39.22 \\ 32.63 \\ 0.0088\end{array}\right]\right] X 106$

The above analysis indicatives that at different temperature range the hydrothermal diffusion effects were evaluated and tested. Since, hydrothermal diffusion usually takes place in the presence of temperature and moisture gradients in the composite materials. At the due temperature and moisture range, the thermal effect on the composite material tailstock dead centre support were also evaluated in different lamina directions [10]. Although based on the above empirical results, we can use tailstock dead cents supports at different conditions. Thus the selected composite materials have good resistance to hydrothermal effects.

\section{Failure Analysis}

A successful design of a structure requires efficient and safe use of materials. Theories need to be developed to compare the state of stress in a material to failure criteria. It should be noted that failure theories are only stated and their application is validated by experiments. Although, for a laminate, the strength is related to the strength of each individual lamina. This allows for a simple and economical method for finding the strength of a laminate. Various theories have been developed for studying the failure of an angle lamina. The theories are generally based on the normal and shear strengths of a unidirectional lamina. Now have design my project using Tsai-wu ${ }_{\text {Failure }}$ Theory because it is the best method from the others but the other is seeing theoretically. $\sigma_{\text {lult }}^{T}$ Ultimate longitudinal tensile strength (in direction 1), $\sigma_{1 \text { ult }}^{c}$ Ultimate longitudinal compressive strength (in direction 1), $\sigma_{2 \text { ult }}^{T}$ ult Ultimate transverse tensile strength (in direction 2), $\sigma_{1 u l t}^{T} \sigma_{2 u l t}^{c}$ Ultimate transverse compressive strength (in direction 2), and $\tau_{12 u l t}=$ Ultimate in plane shear strength (in plane 12).

\section{Maximum stress failure theory}

According to this theory Failure is predicted in a lamina, if any of the normal or shear stresses in the local axes of lamina is equal to or exceeds the corresponding ultimate strengths of the unidirectional lamina.

The lamina is considered to be failed if,

$$
\begin{aligned}
& -\sigma_{1 u l t}^{c}<\sigma_{1}<\sigma_{1 u l t}^{T} \\
& -\sigma_{2 u l t}^{c}<\sigma_{2}<\sigma_{2 u l t}^{T} \\
& -\tau_{12 \mathrm{ul}<\mathrm{\tau} 2}<\tau_{12 \mathrm{ul}}
\end{aligned}
$$

\section{Maximum strain failure theory}

Failure is predicted in a lamina, if any of the normal or shearing strains in the local axes of a lamina equal or exceed the corresponding ultimate strains of the unidirectional lamina. Given the strains/stresses in an angle lamina, one can find the strains in the local axes.

\section{Tsai-Hill failure theory}

This theory is based on the distortion energy failure theory of VonMises' distortional energy yield criterion for isotropic materials as applied to aniso-tropic materials. Distortion energy is actually a part of the total strain energy in a body. The strain energy in a body consists of two parts; one due to a change in volume and is called the dilation energy and the second is due to a change in shape and is called the distortion energy. It is assumed that failure in the material takes place only when the distortion energy is greater than the failure distortion energy of the material

\section{Tsai-wu failure theory}

This failure theory is based on the total strain energy failure theory of Beltrami. Tsai-Wu9 applied the failure theory to a lamina in plane stress. A lamina is considered to be failed if, $\mathrm{H}_{1} \sigma_{1}+\mathrm{H}_{2} \sigma_{2}+\mathrm{H}_{6} \tau_{12}+\mathrm{H}_{11} \sigma_{1}^{2}+$ 
$\mathrm{H}_{22} \sigma_{2}{ }^{2}+\mathrm{H}_{66} \tau_{12}+2 \mathrm{H}_{12} \sigma_{1} \sigma_{2}<1$ is violated. This failure theory is more general than the Tsai-Hill failure theory because it distinguishes between the compressive and tensile strengths of a lamina is as.

$$
\begin{gathered}
\sigma_{1 u l t}^{c}=\sigma_{1 u l t}^{T}=880 \mathrm{Mpa}, \sigma_{2 u l t}^{c}=\sigma_{2 u l t}^{T}=60 \mathrm{Mpa} \text { and } \tau_{12 \mathrm{u}}=97 \mathrm{Mpa} \\
\sigma_{1}=39.22 \mathrm{Mpa} \sigma_{2}=32.63 \mathrm{Mpa} \tau_{12}=-0.0088 \mathrm{Mpa}
\end{gathered}
$$$$
\begin{aligned}
& H_{1}=\frac{1}{\sigma_{1 u l t}^{T} 1}-\frac{1}{\sigma_{1 u l t}^{c}}=\frac{1}{880 \mathrm{Mpq}}-\frac{1}{880 \mathrm{Mpa}}=0 \\
& H_{11}=\frac{\sigma_{1 \text { ult }}^{T} \sigma_{\text {lult }}^{c}}{\sigma^{2}}=\frac{1.2 \times 10-18}{880 \mathrm{MpaX} 880 \mathrm{Mpa}}=1.2 \times
\end{aligned}
$$$$
H_{2}=\frac{1}{\sigma_{2 u l t}^{T}}-\frac{1}{\sigma_{2 u l t}^{c}}=\frac{1}{60 M p a}-\frac{1}{60 \mathrm{Mpa}}=0
$$$$
H_{22}=\frac{1}{\sigma_{2 u l t}^{T} \sigma_{2 u l t}^{c}}=\frac{1}{60 M p a x 60 \mathrm{Mpa}}=1 \times 10^{-16}
$$$$
H_{66}=\frac{1}{\tau_{12}^{2}}=1 / 97 \mathrm{Mpa} \times 97 \mathrm{Mpa}=1 \times 10^{-16}
$$$$
\mathrm{H}_{6}=0
$$$$
H_{12}=\frac{1}{\sigma_{1 t}^{2}}
$$$$
H_{12}=\frac{1}{(880 M p a)^{2}}=1.3 \times 10^{-18}
$$

$\mathrm{H}_{1} \sigma_{1}+\mathrm{H}_{2} \sigma_{2}+\mathrm{H}_{6} \tau_{12}+\mathrm{H}_{11} \sigma_{1}^{2}+\mathrm{H}_{22} \sigma_{2}^{2}+\mathrm{H}_{66} \tau_{12}+2 \mathrm{H}_{12} \sigma_{1} \sigma_{2}<1$

$0+0+0+1.2 \times 10^{-18 \mathrm{x}} 39.22 \times 10^{6}, 2+1 \times 10^{-16 \mathrm{x}} 32.63 \times 10^{6}+1 \times 10^{-16 \mathrm{x}}$ $-0.0088 \mathrm{Mpa} \times 10^{6}+2 \mathrm{x} 1.3 \times 10^{-18} \times 39.22 \times 10^{6 \mathrm{x}} \times 32.63 \times 10^{6}<13.32 \times$ $10^{-2}<1,0.03<1$ the condition is satisfy then the design i(layer) is safe.

\section{Beam analysis}

The torque T, transmitted by the Arebor shaft is given as:

$$
\left.T=\frac{\tau \pi D 3}{16 X t}=97 \times 106 \times 3.14 \times 0.0022 \mathrm{~m}\right) 3 / 16 \times 0.88 \times 10^{-4}=50.7 \times
$$

$103 \mathrm{Nm}$

Weight of Arebor $\left.(\mathrm{W})=\frac{\rho \pi D 2 x L}{4}=1600 \mathrm{~kg} / \mathrm{m}^{3} \times 3.14 \times 0.022\right) 2 \times$
$\mathrm{m} / 4=0.243 \mathrm{~kg}$

The shearing load (Nxy) is defined by Equation $\mathrm{N} / \mathrm{m}$

$N x y=\frac{T}{2 x \pi x r 2}=50.7 \times 103 / 2 \times 3.14 \times(0.022 \mathrm{~m}) 2=166.803 \times 104$

$$
E x=\frac{\sigma x}{£ x}=39.63 \times 10^{6} / 155.76 \times 10^{-6}=2.54 \times 10^{-1} \mathrm{pa}
$$

$\mu=$ poisons ratio $=0.27$

$$
\begin{aligned}
& E y=\frac{\sigma y}{£ y}=\frac{32.63 \times 10^{6}}{5529.76 \times 10^{-6}}=5.9 \times 10^{-3} \mathrm{pa} \\
& G x y=\frac{\tau x y}{\gamma x y}=\frac{0.0088 \times 10^{6}}{1.52 \times 10^{-6}}=5.8 \times 10^{-3} \mathrm{~Pa}
\end{aligned}
$$

$\sigma=\mathrm{Mc} / \mathrm{I}, \mathrm{c}=\mathrm{z}$ distance from neutral axis to top/bottom

$$
I=\frac{3.14 x(d o-d i) 4}{64}=3.14 x(0.022) 4 / 64=1.149 \times 10^{-8} \mathrm{~m}^{4}
$$

$$
C=\frac{\sigma \mathrm{xI}}{\mathrm{M}}=880 \times 10^{6} \times 1.149 \times 10-8 / 57.38 \times 103=1.45 \times 10^{-4} \mathrm{~m}
$$
$\mathrm{m}^{3}$

Section modulus $\mathrm{Z}=\mathrm{I} / \mathrm{c}=1.149 \times 10^{-8} \mathrm{~m}^{4} / 1.45 \times 10^{-4} \mathrm{~m}=7.92 \times 10^{-3}$

The above analysis indicates, the twisting effects of the given material were checked and tested in proper way. Since, the twisting analysis has been performed using mathematical methods and the result assures that the given selected materials have good resistance to rotational force. Hence the materials resistance to twisting effects in different conditions. However, opposite materials have effective and efficient mechanical and physical properties that are now being utilized in manufacturing industries. Since, in this study the analysis of composite materials in the replacement of tradition materials were done. Thus replacement of composite materials has resulted in considerable amount of weight reduction, improving stiffness, thermal resistance, durability properties seen, when compared to conventional steel mechanical components. Since the replacement of steel dead centre support from composite materials were proper done in this study.

\section{Conclusion}

In this study the design analysis and manufacturing of tailstock dead centre were done from composite materials, so as to improve the property and performance of mechanical elements. Using empirical method the replacement of traditional material by well known and suitable composites materials were made with the combining two materials where one of the materials as reinforcement and the other material used as a matrix. However, the replacement of convention steel material to composite materials were much effective than the existing condition in terms of weight reduction, improve stiffness, high thermal resistance and optimizing total costs. Since according to the result indicates the weight reduction of materials replacement were ranges $43 \%$ when compared to conventional steel tailstock dead center support. Although design and analysis for the replacement of tailstock dead centre support from HS Carbon/Epoxy composite were effective than other composite materials when we use in this analysis. In conclusion the result directs strong, light weight, safe and economical tailstock supports were made from HS Carbon/Epoxy material composite materials using filament winding process.

\section{Recommendation}

This study knocks the door for the replacement of traditional materials to composite materials. Since, manufacturing industries, researchers also further investigate to use other composite materials, for different applications.

\section{References}

1. Saini P, Goel A, Kumar D (2013) Design and analysis of composite leaf spring for light vehicles. Int J Innov Res Sci Eng Technol 2: 5.

2. Gururaja MN, Rao ANH (2012) A review on recent applications and future prospectus of hybrid composites. Int J Soft Comput Eng 1: 6.

3. Tafesse G (2010) Composite material lecture notes. Adais ababa Univerity AAiT, Addis Ababa

4. Rambabu K, Rompicharla RPK (2012) Design and optimization of drive shaf with composite materials. Int J Mod Eng Res 2: 5.

5. Nagavally RR (2016) Composite materials-History, types, fabrication techniques, advantages, and applications. In: Proceedings of 29th IRF International Conference, Bengaluru, India.

6. Andersson F, Hagqvist A, Sundin E, Björkman M (2014) Design for 
Citation: Dametew AW (2017) Design and Empirical Analysis of Selected Machine Elements from Composite Materials is Better to Use. Int J Swarm Intel Evol Comput 6: 157. doi: 10.4172/2090-4908.1000157

Page 14 of 14

manufacturing of composite structures for commercial aircraft: The development of a DFM strategy at SAAB Aerostructures. In: Variety Management in Manufacturing Proceedings of the 47th CIRP Conference on Manufacturing Systems, Sewden.

7. Aboudi J (1991) Mechanics of composite materials. Elsevier Sci 29.
8. Gay D (2014) Composite materials: Design and applications. Third edition, CRC Press

9. Crawford RJ (1998) Plastics engineering. Third edition

10. Kaw KA (2006) Mechanics of composite materials. 2nd edition, Tailer and France group. 